\title{
EL LEGADO DE MIGUEL DE CAPIELLA Y LA LABOR ASISTENCIAL DE LA COFRADÍA DE SANTA FE
}

\author{
THE LEGACY OF MIGUEL DE CAPIELLA AND THE CARE WORK \\ OF THE BROTHERHOOD OF SANTA FE
}

Resumen: La cofradía de Santa Fe se fundó en 1218 en la parroquia de San Gil de Zaragoza. En 1392, Miguel de Capiella, un rico ciudadano zaragozano, legó en su testamento la mayor parte de su fortuna para que esta hermandad se ocupase de auxiliar a pobres y huérfanas. Este documento rigió la misión y la financiación de la cofradía y fue el justificante que legitimó a los parientes del testador a ocupar una de las dos capellanías perpetuas que éste ordenó para mantener su memoria y garantizar la salvación de su alma. El texto fue copiado a lo largo de los años y consiguió perpetuar el recuerdo de Miguel de Capiella.

Palabras clave: Testamento, Miguel de Capiella, Cofradía, Santa Fe, Zaragoza.

\author{
M. á Ángeles Montanel Marcuello \\ Universidad de Zaragoza
}

\begin{abstract}
The brotherhood of Santa Fe was founded in 1218 by the church of San Gil in Zaragoza. In 1392, Miguel de Capiella, a wealthy citizien of Zaragoza, left, in his testament, most of his fortune to this fraternity to help poor and orphaned girls. This document guided the mission and the financing of this brotherhood, but it was justifiably a way to prove the right to manage one of the two perpetual chaplaincies created by Capiella to sustain his remembrance and save his spirit. Therefore, the testament has been copied over the years keeping the memory of Miguel de Capiella.

Key words: Testament, Miguel de Capiella, Brotherhood, Santa Fe, Saragossa.
\end{abstract}




\section{Introducción}

Las cofradías surgieron en los reinos hispánicos en época medieval, cuando el asociacionismo fue un fenómeno muy extendido. Los hombres y las mujeres se agruparon para obtener protección física, ecónomica o sentirse integrados en la comunidad. En el siglo XII aquellos que ejercían la misma profesión se constituyeron en gremios, que fueron regulados por los fueros municipales. Muchos de estos colectivos practicaron una solidaridad mutua en casos de enfermedad, cautiverio o accidente. También celebraban cultos de tipo religioso y se dispensaban acompañamiento cuando sobrevenía la muerte. ${ }^{1}$

M. ${ }^{a}$ Isabel Falcón (Falcón: 1997) estudió los gremios de Zaragoza en la Baja Edad Media. Según la autora, al principio, estas asociaciones tuvieron un fin religioso, benéfico y asistencial. Aunque en el siglo xv las cofradías adquirieron un matiz económico más marcado, nunca perdieron su carácter piadoso. Esther Tello (Tello: 2013, 90-91) asegura que en época medieval hubo una adscripción de ciertos santos a determinadas profesiones y que algunas órdenes religiosas fomentaron un tipo de devoción concreta. De esta manera, la Iglesia intentaba que la población se identificara con los santos y los considerara modelos a imitar.

La cofradía de Santa Fe de Zaragoza se fundó en 1218, en la parroquia de San Gil. La entidad estuvo formada por hombres nobles, y en sus casi seis siglos de existencia, se dedicó a tareas asistenciales, auxiliando a pobres y ayudando al casamiento de doncellas huérfanas. ${ }^{2}$

1 Vid. (Rumeu de Armas, 1944: 200). M. ${ }^{a}$ Isabel Falcón afirma que en Aragón el término gremio no aparece en la documentación hasta el siglo XVII. Asegura que en las fuentes anteriores a esta época se utilizan las palabras oficio y cofradía para referise a los gremios (Falcón, 1979).

2 El estudio de la cofradía de Santa Fe fue el eje central de mi trabajo final de Máster, Pobreza y marginalidad: la cofradía de Santa Fe y su labor asistencial en la Zaragoza del siglo XVII. El objetivo de la investigación era conocer cómo vivieron los desamparados de la ciudad de Zaragoza en el siglo XVII, a través de la labor de esta institución. Hasta la aparición de la Historia cultural (Burke, 2006: 16 y ss.) en los años setenta del siglo pasado, los historiadores se habían interesado poco por los marginados. Pese a que en el siglo XVII las cofradías fueron muy numerosas en Zaragoza, no existen en la actualidad muchos trabajos al respecto. Por ello, consideré oportuno aproximarme a los pobres y desvalidos a través de una de estas organizaciones. Para ello, realicé un análisis fundamentalmente cualitativo de fuentes primarias y secundarias, dentro del modelo interpretativo de la microhistoria. De esta manera, intenté reducir la escala de observación del contexto histórico -una cofradía- para estudiar a través de una pequeña parte, problemas generales - las formas de vida de los menesterosos de la ciudad de Zaragoza en el siglo XVII- (Levi, 1994). Las etapas del proceso de elaboración del proyecto pueden secuenciarse en cuatro: la aproximación al contexto a través de la lectura de libros y artículos, el estudio de la documentación sobre la cofradía de Santa Fe, el análisis de la información y por último, la presentación de los resultados. Con respecto a la documentación 
En la documentación conservada de esta cofradía, que se custodia en el Archivo Diocesano de Zaragoza -ADZ-, las primeras ordenaciones datan de 1494. Posteriormente, éstas fueron reformadas en 1692. De estos últimos estatutos se desprende que la institución siempre estuvo constituida por unos $10 \mathrm{o}$ 12 cofrades del sexo masculino. Aunque no se hace alusión explícita a la prohibición de que las mujeres formaran parte de la organización, no hay referencia alguna a cofradesas o nombres de mujer, cosa que sí ocurría en las ordenanzas de otras hermandades de la época. ${ }^{3}$

Los cofrades de Santa Fe pertenecían a las mejores familias de la nobleza zaragozana. Estos hombres tenían la obligación de acudir a los aniversarios por los hermanos difuntos y también gozaban del privilegio de poder enterrarse dentro de la parroquia de San Gil, en la capilla de Santa Fe. ${ }^{4}$

Según Pilar Gay Molins, (Gay, 1983: 13-14) la cofradía contaba con una serie de capellanías financiadas con rentas que provenían de censos y treudos con los que se pagaban a los beneficiados. Dos de estas capellanías - una bajo la invocación de Santa María y la otra bajo la de san Gil- fueron instituidas en el testamento de Miguel de Capiella, a finales del siglo XIv.

Miguel de Capiella fue un rico ciudadano zaragozano, experto en Derecho, que en 1392 legó la mayor parte de su fortuna a la cofradía de Santa Fe para que ésta asistiese a pobres verdaderos y vergonzantes y ayudara al casamiento de huérfanas, mediante la concesión de dotes. El documento donde Capiella ordenó sus últimas voluntades refleja muy bien la mentalidad de la época y sigue al pie de la letra el esquema de los testamentos medievales. ${ }^{5}$

utilizada, consulté fuentes secundarias -bibliografía que me ayudó a comprender el entorno social, mental y político, de la época donde la cofradía de Santa Fe llevó a cabo su actividad- y primarias, la mayoría de ellas custodiadas en el Archivo Diocesano de Zaragoza -ADZ-. Allí se conservan 42 cajas con documentación relativa a esta institución desde el siglo XIV al XVIII. Estos documentos fueron catalogados por Pilar Gay Molins Vid. (Gay, 1983). Pese a que el período objeto de interés era el siglo XVII, hay que tener en cuenta que las viejas estructuras de la sociedad medieval comenzaron a tambalearse en la Baja Edad Media y continuaron con su transformación en la Edad Moderna. Por ello, la consulta de la bibliografía centrada en el período bajomedieval ha sido fundamental para entender: el cambio de actitud hacia el pobre, el funcionamiento de las cofradías y las actitudes de los aragoneses frente a la muerte.

3 En algunas ordenaciones de cofradías zaragozanas del siglo xviI se menciona expresamente a los cofrades y cofradesas, por ejemplo: la cofradía de San José de blanqueros de escobilla y otros gremios Vid. ADZ, Registro Decretos, 1683-1687, f.234r.- f.239r. o la cofradía de Nuestra Señora Baldesca Vid. ADZ, Registro Decretos, 1672-1682, f.19r.-f.25v.

4 Vid. ADz, Archivo Parroquial de San Gil, Procesos Beneficiales, San Gil, núm. 82, Caja 41.

5 Vid. (Gay, 1983:14). 
Para entender el texto ha sido necesario conocer las estructuras sociales, económicas y culturales de la época en la que se generó, y de esta manera, lograr encuadrarlo dentro de la forma de pensar de su tiempo. Como explica $\mathrm{M}^{\mathrm{a}}{ }^{\mathrm{a}}$ Luz Rodrigo (Rodrigo, 2002: 147), la salvación fue la gran obsesión de los aragoneses y aragonesas en la Baja Edad Media, y por ello, cualquier hombre o mujer invertía gran parte de sus bienes en la redención de su alma y la de sus ancestros. Por otra parte, tal y como asegura M. Teresa Iranzo (Iranzo, 2014) en esta época también era fundamental el mantenimiento de la memoria del linaje.

En la Baja Edad Media los hombres de leyes estuvieron muy próximos al poder real y municipal; algunos de ellos, formaron parte de los órganos consultivos de la monarquía. Según Enrique Mainé (Mainé, 2006: 85-91), Miguel de Capiella, fue uno de esos sabios en Derecho al que el rey le encomendó los juicios que tuvieran que ver con el cobro del impuesto de la «marca». Junto con otros juristas y mercaderes como Ramón de Torella, Beltrán de Coscó o Ramón de Casaldáguila, Capiella fue uno de los principales propietarios de la deuda pública emitida por la ciudad de Zaragoza y otros lugares, como Letux, Belchite, Lécera, Fraga, Calcena o la judería de Daroca. ${ }^{6}$

\section{El testamento de Miguel de Capiella}

El legado de Capiella nutrió durante varios siglos la obra benéfica de la cofradía de Santa Fe. Tal y como se desprende de las ordenaciones de 1692, las rentas de la cofradía y las de la ejecución del testamento de Capiella, quedaban claramente separadas, había dos mayordomos - uno para cada negociado- y la contabilidad de cada sección se llevaba a cabo de manera independiente.?

Este «sabio en dreyto» ordenó entre sus últimas voluntades que sus mandas piadosas y los bienes necesarios para llevarlas a cabo fueran gestionados por el vicario de la iglesia de San Gil y uno de los mayordomos de la cofradía de Santa Fe. Además, para garantizar la salvación de su alma fundó en dicha parroquia dos capellanías perpetuas, una bajo la advocación de san Gil y otra

6 Vid. (Mainé, 2006: 85-91). Cada manda piadosa que Miguel de Capiella ordenó en su testamento iba acompañada de la financiación que debía sufragarla. Vid. Testamento de Miguel de Capiella ADZ, Archivo Parroquial de San Gil, Procesos Beneficiales, San Gil, caja 41, núm. 82.

7 Vid. Ordenaciones de la cofradía de Santa Fe, 1692. Adz, Archivo Parroquial de San Gil, Cofradía de Santa Fe, Caja 26, núm.81. 
bajo la de Santa María. Su testamento fue redactado en Zaragoza el 6 de septiembre del año 1392 ante el notario Sancho Martínez de la Peyra. ${ }^{8}$

En el ADZ se conservan varias copias del documento -dos manuscritas en pergamino y una impresa en papel-. El texto que he analizado es el cuadernillo impreso, que se adjuntó al proceso beneficial de Fernando Abad, quien en 1712 optó a la capellanía que había quedado vacante bajo la advocación de Nuestra Señora.

En el testamento aparece la invocación simbólica -representada con una cruz- y la invocación explícita: «En el nombre de Dios y de la suya gracia, Amen». Después, el otorgante explica la razón que le lleva a redactar sus últimas voluntades: «Sepan todos, porque alguna persona en carne puesta, a la muerte corporal escapar no puede».

A continuación, aparece la notificación objetiva: «por aquesto yo» y la intitulación: «Don Miguel de Capiella, sabio en dreyto, ciudadano de Zaragoça», al tiempo que se describe su situación en ese momento: «siendo sano a la merced de Dios y en mi buen seso, firme memoria y entrega palavra». Posteriormente, revoca todos los testamentos y codicilos anteriores y anuncia que procede a manifestar sus últimas voluntades. ${ }^{10}$

En el dispositivo o eje documental, Capiella trata de reparar los entuertos, deudos e injurias que ha cometido en vida y ordena su sepultura. El lugar elegido para ello es el convento de los Frailes Menores de Zaragoza -convento de

8 Vid. Testamento de Miguel de Capiella ADz, Archivo Parroquial de San Gil, Procesos Beneficiales, San Gil, caja 41, núm. 82.

9 ADz, Archivo Parroquial de San Gil, Procesos Beneficiales, San Gil, caja 41, núm. 82.

10 En la intitulación Miguel de Capiella señala su condición de ciudadano. Según Enrique Mainé los ciudadanos contaban con plenitud de derechos, pertenecían a la elite privilegiada y así lo hacían constar en la documentación. El 24 de septiembre de 1348, Pedro IV concedió a los ciudadanos honrados de Zaragoza -aquellos que tenían caballo propio y no se manchaban las manos trabajandouna serie de privilegios que consistían en: la exención del pago del monedaje, la transmisión de la inmunidad fiscal, exenciones regias y vecinales para todas sus posesiones muebles e inmuebles en cualquier punto del reino donde se encontraran y la posibilidad de armarse caballeros sin especial licencia regia. En la Baja Edad Media la población de Zaragoza se dividía en: habitantes, vecinos y ciudadanos. Los habitantes eran personas que estaban de paso, recién llegados o pobres gentes sin recursos. Los vecinos tenían que poseer vivienda en propiedad, residir en ella y contribuir a las cargas municipales. Los ciudadanos contaban con la protección jurídica del fuero y gozaban de privilegios otorgados por la monarquía a la ciudad -el derecho al disfrute de los bienes comunes y la participación en la vida política-. Sólo este grupo podía acceder a las altas magistraturas del gobierno municipal. A diferencia de Huesca, en Zaragoza la nobleza urbana quedó apartada del gobierno municipal. La nobleza en Zaragoza no soportaba cargas vecinales, por ello hubo quien se hizo pasar por infanzón sin serlo (Mainé, 2006: 11-24). 
San Francisco- ${ }^{11}$ en una capilla construida por él y dedicada a San Luis y San Matías donde quiere reposar junto a sus padres y su hermana. ${ }^{12}$

Posteriormente, destinó 4.000 sueldos jaqueses para los gastos del funeral, el entierro y los sufragios por la salvación de su alma y las de sus ancestros difuntos. Para sus exequias ordenó que su cuerpo se cubriese con dos paños de oro y que posteriormente, éstos se donaran: uno al convento donde iba a ser enterrado y otro a la iglesia de San Gil..$^{13}$

Estableció el pago a los religiosos, a los rectores y a los vicarios de la ciudad que acudieran a su entierro. Además, ordenó que se vistiera de luto a 15 pobres: 5 mujeres y 10 hombres y que éstos últimos se encargasen de trasladar su cuerpo a enterrar. ${ }^{14}$

Ordenó misas y sufragios, novena, oblada y candela durante un año con ofrendas de cera durante el mismo período, una pitanza en el convento de los Frailes Menores y aniversario el día de su muerte con misa de réquiem. ${ }^{15}$

A continuación, distribuyó sus bienes muebles e inmuebles y dispuso que se acabasen las obras sufragadas por él que ya estuvieran iniciadas en distintos monasterios, conventos e iglesias de la ciudad e incluso de fuera de ella -el monasterio de las Menoretas y el convento de San Agustín en Zaragoza y la iglesia de Santa María de Monserrat-. ${ }^{16}$

11 Vid. (Gay, 1983: 14).

12 Muchos miembros de la nobleza a mediados del Cuatrocientos optaron por enterrarse en los monasterios de Frailes Menores (Rodrigo, 2002: 92-93). Según los sermones de San Vicente Ferrer, en el momento del fallecimiento el alma sufría un primer juicio. Posteriormente, en el Juicio Final cuerpo y alma se reencontrarían tras la resurrección de los muertos y juntas sufrirían el castigo eterno o gozarían de la gloria para siempre. M. ${ }^{a}$ Carmen García y M. Isabel Falcón afirman que en Aragón en el siglo Xv la creencia en el purgatorio estaba totalmente asentada. En este lugar se purificaban las almas de quienes habían muerto siendo pecadores, pero no tanto para ir directamente al infierno. La idea del purgatorio estuvo controlada por la Iglesia, que se presentó ante la población como la gestora de este espacio de esperanza para los muertos y de consuelo para los vivos. Los aragoneses trataban de ayudar a sus seres queridos difuntos con misas o acciones pías que pudieran disminuir el número de años de estancia en tan siniestro lugar (García y Falcón, 2006: 166-167).

13 Era obligado entregar la denominada cuarta funeraria a la parroquia a la que se pertenecía, si se prefería enterrar en otro lugar distinto. Además, se debía pagar al párroco del difunto las cuotas establecidas que se iban revisando periódicamente en los concilios y sínodos provinciales (Rodrigo, 2002: 82).

14 Era habitual que los testadores con posibles pagaran las ropas de luto de quienes querían que lo llevaran. La gente corriente, ante el fallecimiento de un familiar teñía sus ropas habituales. Por lo general, el tiempo de luto acostumbrado era un año, aunque este período se podía alargar o acortar (García y Falcón, 2006: 181).

15 Se creía que la misa era el remedio más eficaz para alcanzar la salvación. Los días claves de las misas eran: el día de la defunción, los nueve días siguientes -novena- y el primer año después de la defunción -cabo de año- (García y Falcón, 2006: 175-178).

16 Según M. ${ }^{a}$ Luz Rodrigo era muy común que los testadores legaran dinero para la iluminación en iglesias alejadas del entorno cotidiano del testador como Santa María de Monserrat, Nuestra Señora del 
En este mismo apartado ordenó que fuera devuelto el ajuar a su mujer y le dejó «todos sus vestidos, joyas y el mas bello jarrón y la más bella copa que tuviera». Para su nieta Florentica dispuso 15.000 sueldos que, como tutor suyo, había recibido para su dote y estableció que si la muchacha muriera sin hijos el dinero se empleara en sostener a necesitados y casar a huérfanas. ${ }^{17}$

También quería que se saldase una deuda que su padre dejó y que se entregaran 2.000 sueldos a los familiares de la que fue su primera mujer, por los beneficios que obtuvo de la venta de sus vestidos y joyas. Asimismo, ordenó que se pagase a los mozos y mozas que trabajaban o habían trabajado en su casa: por lo general, a ellas les otorgó 400 sueldos y a ellos soldada más 100 sueldos.

Para Margalitica, una hija natural suya, legó 20.000 sueldos como ayuda a su casamiento, de los que podría disponer de 3.000 para la salvación de su alma. La muchacha sólo podría acceder a este dinero siempre que su matrimonio recibiese el visto bueno de su tutor, y de tres albaceas del testamento. $\mathrm{Si}$ Margalitica no se casara conforme a la opinión de la mayoría de estas personas o no tuviera hijos legítimos, su dote se destinaría a ayudar a pobres y al casamiento de huérfanas.

Capiella dispuso que se trasladasen los cuerpos de sus padres y hermana desde el claustro del convento de San Francisco a la capilla que él ordenó construir en ese cenobio, bajo la advocación de san Luis y san Matías. Las sepulturas de sus padres deberían quedar dispuestas a la derecha del altar y la de su hermana a la izquierda, y sobre ellas, debían figurar los escudos de su padre y el suyo. Para el sepulcro de su hermana, ordenó que se labrase la siguiente inscripción: «Aqui jacen, o son los huesos de Maria Sanchez de Capiella, filla de D. Juan de Capiella que fueron». ${ }^{18}$

Pilar de Zaragoza, Santa María de Burgos o Santa María de la Peña de Francia. La autora asegura que estas cantidades solían ser exiguas, entre seis dineros y cinco sueldos (Rodrigo, 2002: 157). Capiella, dejó 1.000 sueldos, lo que nos da una idea del potencial económico de este ciudadano zaragozano.

17 En la copia impresa del testamento de Capiella se dice que deja a su mujer «todos sus vestidos, joyas y el bel mas del piebrer? y la más bella copa que tuviera». Uno de los manuscritos, el que copió el notario Juan Manent, presenta una mancha en este trozo del texto. La copia del notario Antón Calvo datada el 15 de junio de 1483 está mucho mejor conservada y en ella leemos «todos sus vestidos, joyas et el mas bel piger e la mas bella copa que yo tengo». Según la doctora Asunción Blasco Martínez, piger hace referencia a pitxer, palabra de origen valenciano, cuya traducción al castellano es 'jarra o jarrón'. ADZ, Archivo Parroquial de San Gil, Procesos Beneficiales, San Gil, caja 41, núm. 82 y Adz, Archivo Parroquial de San Gil, Cofradía de Santa Fe, C6-1.

18 ADZ, Archivo Parroquial de San Gil, Procesos Beneficiales, San Gil, caja 41, núm. 82. 
Por otra parte, el otorgante fundó dos capellanías perpetuas en la iglesia de San Gil, una en el altar de dicho santo y otra en el de Santa María, para que se celebrasen misas diarias por su alma y la de sus ancestros, durante toda la eternidad. Capiella estableció que estos patronatos gozaran de unos privilegios, en los que ni el papa, ni el arzobispo, ni eclesiásticos o seglares pudieran inmiscuirse. ${ }^{19}$ Dos patrones deberían velar por el correcto funcionamiento de ambas fundaciones. El primero debía ser su heredero o el tutor de éste, que desempeñaría esta función si el óbito del testador acaecía antes de la mayoría de edad de su sucesor. Posteriormente, el cargo se iría transmitiendo, preferentemente, sobre la línea paterna de la familia. Si no existieran sucesores aptos, el vicario de San Gil y uno de los mayordomos de la cofradía de Santa Fe deberían asumir su gestión. La financiación de estas capellanías debía ser sostenida con treudos.

Además, estableció que se atendiera diariamente a 13 pobres «clamantes de Dios en el spital de Santa Fe». Debían ser: 8 hombres y 5 mujeres, cuyo sustento supondría un gasto anual de 2.372 sueldos y 6 dineros. El vicario de San Gil y el mayordomo de Santa Fe debían decidir quiénes recibirían la ayuda, además de ocuparse de gestionar los dos treudos perpetuos situados en Calcena y Belchite que financiaban esta causa. Otra manda fue destinar 1.000 sueldos anuales para casar a huérfanas. Las muchachas deberían recibir 200 sueldos como dote o 500, si éstas eran parientes suyas hasta el quinto grado. Para sufragar esta obra, el testador dejó dos censos de 500 sueldos cada uno en las localidades de Lécera y Fraga. Igualmente, ordenó otros 1.000 sueldos al año para atender a pobres vergonzantes. Aquellos que fueran parientes suyos recibirían 200 sueldos anuales y el resto 100 sueldos por año. El importe de esta obra pía se costearía con sendos censos ubicados en Letux y Belchite.

Por último, estableció que se celebrasen 12 aniversarios anuales perpetuos por las ánimas de sus padres, hermanos, mujeres e hijos y por la suya propia. El importe de cada aniversario era de 10 sueldos y debían celebrarse en la iglesia de San Gil.

El vicario de San Gil y el mayordomo de la cofradía de Santa Fe, serían elegidos por un año y tenían como obligación gestionar el patronato de las capellanías y asistir a los pobres y las huérfanas. Por su trabajo, cobrarían 100

19 Una capellanía era una fundación donde una persona legaba un patrimonio que beneficiaría a un clérigo a cambio de que éste celebrase misas por el alma del fundador y sus parientes. Las misas se oficiaban en una capilla, por ello se llamaban capellanía. (Teruel, 1993: 63-68). 
sueldos anuales respectivamente y tenían potestad para hacer albaranes y comprar treudos con los que poder ejecutar la labor que Miguel de Capiella les encomendó.

En la parte final del testamento o escatolo, el otorgante eligió como tutor de los hijos menores a Juan de Capiella, de quien sólo sabemos que era notario. A juzgar por su apellido, pudiera ser familia del testador, tal vez un hermano, aunque en el testamento no se indica si existía algún grado de parentesco entre ellos. Para administrar este inmenso legado, el otorgante eligió a seis «espondaleros», todos hombres, y muy poderosos, entre los que figuraba el Justicia de Aragón. ${ }^{20}$

El testamento, como prescribía el fuero aragonés, contó con dos testigos. El texto está datado el 6 de septiembre de 1392 en Zaragoza y lo firma Sancho Martínez de la Peyra, notario público de esta ciudad. ${ }^{21}$

\section{El proceso beneficial de Fernando Abad}

La copia del testamento que he analizado forma parte de un proceso beneficial que tuvo lugar en 1712. En él, Fernando Abad, por medio de su procurador, exponía ante Don Antonio de Peralta -oficial eclesiástico principal de la ciudad de Zaragoza- los motivos por los cuales aspiraba a una de las dos capellanías que, bajo la invocación de Santa María, Capiella ordenó fundar tras su muerte.

La exposición de Fernando Abad se dividió en varios artículos. En primer lugar, se aludió al testamento de Capiella y a las capellanías que éste dispuso. El procurador de Abad argumentó que en ese momento no existía ningún des-

20 Según Enrique Mainé, Juan de Capiella era notario y parroquiano de San Gil. En su notaría registró las actividades de la parroquia -reuniones del capítulo parroquial y actividades de la cofradía de Santa Fey sus parroquianos, entre los que había importantes mercaderes (Mainé, 2006: 132). Los espondaleros, también llamados cabeçaleros o executores, eran las personas que el testador designaba como albaceas para asegurarse de que sus últimas voluntades serían ejecutadas. Vid. (Rodrigo, 2002: 181-187).

21 Ana del Campo clasifica el ordenamiento jurídico de Aragón en la Edad Media en tres grandes períodos. El primero, durante los siglos XI y XII, momento en el que se generaron los primeros ordenamientos, donde encontramos tres tipos de foralidad que el profesor Lalinde dividió en: fueros burgueses, militares y de extremadura. La segunda fase tuvo lugar en el siglo xIII donde las leyes tuvieron una índole militar y se produjo la primera gran compilación encargada al obispo de Huesca, Vidal de Canellas. Los fueros de Aragón fueron promulgados el 6 de enero de 1247. El tercer y último período tuvo lugar durante el siglo XIV y la primera mitad del Xv, donde según la autora, los fueros se nacionalizaron y adoptaron un claro carácter pactista (Del Campo, 2006: 425-427). 
cendiente, deudo, ni pariente del testador, y por ello, el patronato de ambas había recaído en el vicario de San Gil y el mayordomo de Santa Fe. Gaspar Romero, quien hasta entonces había sido el beneficiado de la capellanía pretendida, había muerto. Por este motivo, Fernando Abad fue presentado por el entonces vicario de San Gil -Félix Chabarria- y el mayordomo de la cofradía de Santa Fe -Félix de Rebolledo y Palafox- para ocupar la vacante. El aspirante alegó que era sacerdote y «persona honesta y recatada de buenas y loables costumbres, buen cristiano temeroso de Dios y de su conciencia», que no era titular de ningún otro beneficio y que estaba dispuesto a cumplir las obligaciones inherentes al cargo, por lo que, a través de su procurador solicitó a la autoridad eclesiástica que le fuera concedido dicho beneficio. Por último, se adjuntó una reproducción impresa del testamento de Miguel de Capiella. De esta manera, este documento medieval fue copiado a comienzos del siglo XVIII. ${ }^{22}$

Sin embargo, esta no es la única copia conservada del testamento. En el ADZ se conservan dos pergaminos manuscritos del texto. Uno de ellos, data del 15 de junio de 1483 y fue trasladado por Antón Calvo de Torla, quien fue «notario público de la ciudad de Zaragoza y por autoridad real de los reinos de Aragón y Valencia». ${ }^{23}$ Según este fedatario los jurados de la ciudad le hicieron llegar las notas originales del notario Sancho Martínez de la Peyra. En el segundo texto no aparece la data cronológica, pero sí la firma del notario público de la ciudad de Zaragoza Juan Manent. Al igual que en el caso anterior, Manent asegura que se ha basado en las notas originales de Martínez de la Peyra, que los jurados de Zaragoza le han entregado. ${ }^{24}$

22 ADZ, Archivo Parroquial de San Gil, Procesos Beneficiales, San Gil, caja 41, núm. 82.

23 ADZ, Archivo Parroquial de San Gil, Cofradía de Santa Fe, C6-1. Según Germán Navarro se conservan los libros del notario Antón Calvo desde 1451 hasta 1491. El notario tenía el derecho y la obligación de guardar las notas que servían de base para redactar el documento original, tanto los libros de notas -manuales o protocolos- como los registros -o copias en extenso y sin abreviaturas de esos documentos- (Navarro, 2004: 56-60). La doctora Asunción Blasco ha estudiado el notariado de Zaragoza de los siglos XIII y XIV y tiene publicados un gran número de trabajos al respecto. Según la profesora, en Aragón en los siglos XIV y XV se denominaba notario al profesional que autorizaba los actos extrajudicales y los contratos y escribano a quien ejerecía la función en la esfera judicial, en la corte o en el concejo. El notario además de escriturar tenía fe pública. Esta prerrogativa la recibía por autoridad del rey, el papa, el obispo, los munícipes o el señor laico o eclesiástico. Para ser notario se requería ser varón de cierta edad, libre, cristiano y seglar, de buena fama y sanas costumbres. La legislación sobre el notariado se remonta a los fueros. En 1391 Juan I trató de evitar la venta indiscriminada de las notarias y la pérdida o extravío de los libros notariales autorizando a los jurados de Zaragoza, que junto con los miembros del concejo o la mayor parte de ellos, proveyeran las notarías de la ciudad que quedaran vacantes y controlaran el traspaso de los protocolos (Blasco, 2015: 95-97).

24 ADZ, Archivo Parroquial de San Gil, Cofradía de Santa Fe, C6-2. 
De acuerdo con el libro de finales del siglo XviII titulado Origen y Estado del Colegio de los notarios de número de Zaragoza, que actualmente se conserva en el Archivo Histórico Provincial de Zaragoza -AHPZ-, sabemos que en aquella centuria la escribanía de Sancho Martínez de la Peyra y de Juan Manent fueron encomendadas al notario Pablo Nicolás de Villanueva y que las notas del notario Antón Calvo de Torla pasaron al notario Miguel Antonio Villanueva. En el Archivo Histórico de Protocolos Notariales de Zaragoza -AHPNZ- se conservan protocolos de Sancho Martínez de la Peyra entre los años 1363 a 1389 y de Antón Calvo entre los años 1451 y 1491. Sin embargo, parece ser que no existen en dicho archivo protocolos de Juan Manent. ${ }^{25}$

De entre las varias copias del testamento - una para cada «espondalero»que en su momento debieron existir, al menos tres de ellas se han conservado junto con la documentación de la cofradía de Santa Fe. Aunque no sabemos con qué finalidad fueron copiados estos textos ni quién ordenó su elaboración, no es difícil imaginar que a la hermandad le interesara conservar el documento, ya que en él se basaba una parte muy importante de su misión y su funcionamiento. También resulta obvio que el escrito fuera de vital importancia para el vicario de San Gil, para cualquier aspirante que optase a ser beneficiado de alguna de las dos capellanías y para las huérfanas o pobres vergonzantes parientes del testador. ${ }^{26}$

\section{Conclusiones}

Miguel de Capiella quiso trascender a la muerte, y con este fin diseñó el lugar para el reposo de su cuerpo -junto a sus padres y hermana- donde debían lucir los escudos familiares; concedió dotes a su hija y a su nieta con el objeto de que contrajesen matrimonio y tuvieran hijos legítimos y que éstos llevaran su nombre y sus armas; ordenó doce aniversarios anuales perpetuos, que debían celebrarse en la parroquia de San Gil, y fundó dos capellanías para que se celebrase una misa diaria por su espíritu y el de sus antepasados.

25 Vid. el libro impreso por Mariano Miedes a finales del siglo XVIII, Origen y Estado del Colegio de los notarios del número de Zaragoza, 1794 (Miedes, 1794: 95 y 129).

26 En el testamento se estableció que el notario debía entregar una copia a cada uno de los 6 espondaleros, encargados de ejecutar las últimas voluntades de Capiella. Por tanto, cabe la posibilidad de que en el Archivo Histórico de Protocolos Notariales-AHPN- se conserven varias copias más del documento. Queda pendiente para futuras investigaciones averiguar esta contingencia. De momento, lo único que he podido comprobar en una visita a dicho archivo es que el libro del notario Sancho Martínez de la Peyra en torno al año 1392 se encuentra bastante deteriorado. 
Lamentablemente, con el tiempo su linaje desapareció. Según Enrique Mainé (Mainé, 2006: 51), Miguel de Capiella murió sin heredero alguno un año después de la redacción de éste, su último testamento. Esta afirmación se puede corroborar en la documentación de la cofradía de Santa Fe. En su archivo se conservan documentos que atestiguan operaciones de compra que Miguel realizó hasta 1393. Después de esta fecha, las siguientes transacciones que afectan a los bienes de Capiella son del año 1398 y no fueron realizadas por él sino por sus albaceas.

De la lectura de la copia del testamento del siglo XVIII se desprende que su primera mujer fue Elvira López de Corbes. Por la documentación de la cofradía de Santa Fe, se sabe que en 1380 esta fémina estaba viva puesto que, junto con su marido vendió un treudo al pellicero Juan de Cariñena y a su esposa, María Serrano. ${ }^{27}$ Muy probablemente fue con Elvira con quien nuestro rico benefactor tuvo una hija llamada Elvira Capiella -que habría fallecido- que se casó con el notario Bellio Aznarez de Garden y con quien tuvo a Florentica, la única nieta viva que Capiella tenía en $1392 .{ }^{28}$ Sabemos, por la misma documentación de la cofradía, que el testador tuvo al menos, otro hijo: Martinico de Capiella quien en 1372 había recibido del rector de Mora una donación de 1.000 sueldos de treudo perpetuo de un censal sobre el concejo de Belchite. ${ }^{29}$

Por desgracia, Martinico habría fallecido antes de la redacción del testamento. En aquellos momentos la familiar más directa de Miguel de Capiella era una hija natural, Margalitica. Sin embargo, el testador todavía albergaba la

27 ADZ, Archivo Parroquial de San Gil, Cofradía de Santa Fe, C3-10.

28 Enrique Mainé indica que Elvira es fruto del matrimonio entre Beatriz López Sarnés y Miguel de Capiella. Elvira adoptó el apellido del padre e interpuso el López de su madre. Elvira López de Capiella se casó en 1385 con el notario Bellio Aznárez de Garden, también ciudadano de Zaragoza. La hija de ambos, heredera de una parte sustancial del legado patrimonial de Miguel de Capiella y de Bellio Aznárez de Garden, aparecía en la documentación como Florenza Aznárez de Garden, alias de Capiella. Ésta tuvo por marido al caballero Pardo Lacasta, uno de cuyos hijos pasaría a llamarse Miguel Capiella. Aunque con los datos disponibles el autor no se atreve a asegurarlo, cree que en el hijo de Florenza confluyó tanto la herencia familiar del linaje de los Capiella como la encomienda de mantener y transmitir este apellido (Mainé, 2006: 51). Sin embargo, de la lectura de la copia impresa del testamento de Capiella, se desprende que la primera mujer de Capiella se llamaba Elvira López de Corbes: «ITEM, quiero que sian dados a Aznar Corbes, y a los fillos de Pedro Lopez del Spital dos mil sueldos, en satisfacion de algunos vestidos, y joyas que yo vendie, que fueron de Elvira Lopez de Corbes primera muller mía que fue». La doctora Asunción Blasco que ha transcrito la copia del notario Antón Calvo, afirma que el nombre que en el documento aparece es Elvira López de Lorbes «Iтем quiero que sian dados a Aznar de Lorbes e a los fillos de Pedro Lopez del espital dos mil solidos en satisfacion de algunos vestidos y joyas que yo vendie, que fueron de Elvira Lopez de Lorbes primera muller mia que fue». ADZ, Archivo Parroquial de San Gil, Procesos Beneficiales, San Gil, caja 41, núm. 82 y ADz, Archivo Parroquial de San Gil, Cofradía de Santa Fe, C6-1.

29 ADZ, Archivo Parroquial de San Gil, Cofradía de Santa Fe, C2-9. 
esperanza de poder concebir a un heredero varón con la que, en aquellos momentos, era su esposa y de la que sólo nos da su nombre, Altadona. Al parecer, su deseo no llegó a cumplirse.

Conocemos que la primera de las capellanías instituidas en la iglesia de San Gil fue ocupada por Nicolás de Alcorisa en el año 1418, tal y como fue encargado por el testador. En 1482 Juan Crespo, alias Capiella, se hizo cargo de la segunda capellanía, lo que demuestra que finalmente Miguel de Capiella murió sin heredero masculino y su linaje desapareció. ${ }^{30}$

La cofradía de Santa Fe, a la que Capiella destinó gran parte de su fortuna, gestionó su legado y con él asistió a pobres y huérfanas durante cuatro siglos. En las ordenaciones de la hermandad de 1692 se advertía que las rentas de la entidad escaseaban y que las mandas del testamento no podían cumplirse tal cual habían sido ordenadas. Es significativo que Miguel de Capiella fijara el salario del vicario de San Gil y el del mayordomo de la ejecución en 100 sueldos anuales y que, tres siglos más tarde, la remuneración de estos cargos se hubiera reducido a la mitad, 50 sueldos. Finalmente, la cofradía desapareció en algún momento comprendido entre 1783 y 1850. Aunque, en el Expediente del Estado de las Cofradías, Hermandades y Congregaciones de la ciudad de Zaragoza, que fue remitido al Consejo de Castilla en 1783, la cofradía de Santa Fe contaba con unas cuentas saneadas y era calificada como cofradía de nobles dedicada a fines benéficos. ${ }^{31}$ En la relación de hermandades de Pascual Madoz del año 1850 la institución ya no aparece ni en San Gil ni en ninguna otra parroquia de la ciudad. ${ }^{32}$

A mediados del siglo XVIII los últimos beneficiados -Francisco Andrés y Pedro de Larra- ostentaron las dos capellanías de la iglesia de San Gil, por tanto, sería en estas fechas cuando se celebrarían las últimas misas por el alma de Capiella y sus antepasados. ${ }^{33}$

Poco después, a comienzos del siglo XIX, los franceses destrozaron el convento de San Francisco durante el segundo sitio que sufrió la ciudad. En aquel edificio estaban enterrados los Capiella junto a otros miembros de la elite zaragozana. Por desgracia, todo terminó siendo pasto de la ruina que provocan las guerras. ${ }^{34}$

\footnotetext{
30 Ver anexos. ADz, Procesos Beneficiales, San Gil, f.313r.-f.314r.

31 AHn, Consejo de Castilla, Estado de las Cofradías, Hermandades y Congregaciones a la ciudad de Zaragoza junto con los pueblos de su jurisdicción, Consejos, 7105, Exp. 64, N.1, f.33. <www.pares. mcu.es> (consulta a 10/viI/2015).

32 Vid. (Madoz, 1981).

33 ADz, Procesos Beneficiales, San Gil, f.313r.-f.314r.

34 Vid. (Armilllas, 1997: 68-69).
} 
En definitiva, ni la descendencia, ni los aniversarios y misas diarias perpetuas, ni las imponentes capillas con hermosas sepulturas donde se inscribieron los nombres y las armas de los Capiella lograron resistir los avatares de la historia. Solo han llegado hasta nuestros días las palabras manuscritas sobre unos pergaminos que, por unos u otros intereses, se conservaron y se copiaron a lo largo de los años. Nunca sabremos si, finalmente, el alma de Miguel de Capiella obtuvo la salvación, pero lo que sí podemos afirmar es que este ciudadano que moró en la Zaragoza del siglo XIV consiguió trascender a la muerte y perpetuar la memoria de su linaje. 


\section{ANEXOS}

\section{Capellanía 1: Invocación de Santa María}

\begin{tabular}{|c|c|c|c|c|}
\hline Año & Día/ Mes & Capellán & Presentado por & $\begin{array}{l}\text { Duración } \\
\text { (años) }\end{array}$ \\
\hline 1418 & Últimos de enero & Nicolás de Alcorisa & & 41 \\
\hline 1459 & Agosto & Antonio Bañau? & & 2 \\
\hline 1461 & 22 de agosto & Juan Crespo, alias Capiella & Gracia y Juan Capiella & 5 \\
\hline 1466 & 23 de enero & Juan Capiella & Gracia Capiella & 10 \\
\hline 1476 & 6 de marzo & Pedro Ximénez de Mostiello & & 2 \\
\hline 1478 & 5 de noviembre & Juan Capiella & Gracia Capiella & 31 \\
\hline 1509 & 5 de septiembre & Martín de Capiella & $\begin{array}{l}\text { María de Capilla y Jaime de } \\
\text { Capiella }\end{array}$ & 0 \\
\hline 1509 & 5 de septiembre & Jaime de Mosclanos & $\begin{array}{l}\text { Martín de Capiella la per- } \\
\text { mutó con Jaime Mosclanos }\end{array}$ & 26 \\
\hline 1535 & 2 de junio & Jaime Calvo & $\begin{array}{l}\text { Miguel Garcés de Capiella } \\
\text { y Pedro Garcés de Capiella. } \\
\text { Vecinos de Castejón de } \\
\text { Valdejasa }\end{array}$ & 4 \\
\hline 1539 & & Jaime Monfort & $\begin{array}{l}\text { A presentación de los mis- } \\
\text { mos Garcenses. }\end{array}$ & 21 \\
\hline 1560 & 2 de noviembre & Domingo Lucón & & 38 \\
\hline 1598 & 9 de abril & Juan Moslanos & Diego Morlanos Larisza? & 24 \\
\hline 1622 & Febrero & Felipe Malo & $\begin{array}{l}\text { Agustín Morlanos, de la } \\
\text { Audiencia Real }\end{array}$ & 20 \\
\hline 1642 & 21 de octubre & Juan Blasco & A presentación del mismo & 34 \\
\hline 1676 & 22 de noviembre & Gaspar Romero & Magdalena Gómez & 36 \\
\hline 1712 & 22 de noviembre & Fernando Abad & $\begin{array}{l}\text { Vicario y Mayordomo de la } \\
\text { cofradía de Santa Fe }\end{array}$ & 52 \\
\hline 1764 & 27 de julio & Francisco Andrés & & $? ? ?$ \\
\hline
\end{tabular}

Fuente: Elaboración propia. ADz, Procesos Beneficiales, San Gil, f.313r.-f.314r. 
Capellanía 2: Invocación de San Gil

\begin{tabular}{|c|c|c|c|c|}
\hline Año & Día/ Mes & Capellán & Presentado Por & $\begin{array}{l}\text { Duración } \\
\text { (años) }\end{array}$ \\
\hline$? ? ?$ & & Juan Crespo & & \\
\hline 1482 & 6 de abril & Alfonso Cisneros & & 9 \\
\hline 1501 & 4 de septiembre & Agustín de Soria & & 43 \\
\hline 1544 & & Gerónimo Cerpen & $\begin{array}{l}\text { Vicario y Mayordomos de la } \\
\text { cofradía de Santa Fe }\end{array}$ & 0 \\
\hline 1544 & 30 de octubre & Juan Bierges & & 25 \\
\hline 1569 & 18 de noviembre & Sebastián Pérez & $\begin{array}{l}\text { Juan Calvo mayor y menor } \\
\text { vecinos de Alcañiz e Híjar }\end{array}$ & 2 \\
\hline 1571 & 24 de agosto & Pedro Canelon & Diego Morlanes & 1 \\
\hline 1572 & 8 de noviembre & Gerónimo Ballabriga & & 5 \\
\hline 1577 & 23 de septiembre & Juan Morlanes & Diego Morlanes & 17 \\
\hline 1594 & 23 de julio & Pedro Rafael & & 18 \\
\hline 1612 & & Antonio Vicenciano & & 11 \\
\hline 1623 & 23 de septiembre & Gerónimo Ramírez & Agustín Morlanos & 3 \\
\hline 1626 & 15 de septiembre & Diego Calixto Ramírez & Agustín Morlanos & 35 \\
\hline 1661 & 6 de abril & Francisco Cardiel & Agustín Morlanos & 7 \\
\hline 1668 & 4 de julio & Francisco Vibes & $\begin{array}{l}\text { Agustín Morlanes Gómez de las } \\
\text { Cuebas }\end{array}$ & 3 \\
\hline 1671 & & José Caballer & $\begin{array}{l}\text { Padre de Joseph Morlanes, } \\
\text { monge Cartujo }\end{array}$ & $? ? ?$ \\
\hline$? ? ?$ & & Francisco Derra & & $? ? ?$ \\
\hline 1735 & 18 de febrero & Pedro de Larra & $\begin{array}{l}\text { Vicario y Mayordomo de la } \\
\text { cofradía de Santa Fe. }\end{array}$ & $? ? ?$ \\
\hline
\end{tabular}

Fuente: Elaboración propia. ADZ, Procesos Beneficiales, San Gil, f.314 r. 


\section{APÉNDICE DOCUMENTAL}

1. Siglo XviI, Zaragoza? ADZ, Archivo Parroquial de San Gil, Procesos Beneficiales, San Gil, caja 41, núm. $82 .{ }^{1}$

\section{$†$ COPIA DEL TRANSUNTO DEL TESTAMENTO DEL QUONDAM DON MIGUEL CAPIELLA}

$/ /{ }^{2}$ EN EL NOMBRE DE DIOS, y de la suya gracia, Amen. Sepan todos, porque alguna persona en carne puesta, a la muerte corporal escapar no puede; por aquesto, yo Don Miguel de Capiella, Sabio en dreyto, Ciudadano de la Ciudad de Zaragoça, siendo sano a la merced de Dios, y en mi buen seso, firme memoria, y entrega palavra; pero como el hombre nació en este mundo, tan cierta cosa como ies la muert, ni tan incierta como ies el dia, hora, y punto de aquella; temiendo las penas del Infierno; y cobdiciando anda a la groria de Paradiso; y por tal, que cada que nuestro Señor Dios ordenará que yo passe de este mundo al otro, por razon de mis bienes entre mi anima, y los parientes mios cercanos contrait, ô quistion alguna nascer, ô feier no pueda, revocando, casando, y anulando todos, y cada unos otros Testament, y Testamentes, Codecill, o Codecillos, y ultimas voluntandes, por mi ante de agora feytos, y ordenados, y feytas, y ordenadas, fago, y ordeno este mi postrimero Testament, ultima voluntad mia, y departimento de mis bens, dus la forma que se sigue. PRIMERAMENT, quiero, mando, y ordeno, que de mis bens sian satisfeitos, pagados, y enmendados todos mis deudos, tuertos, y injurias, aquellos, y aquellas que con cartas, ó por buena verdad serán trobadas, que yo sia tenido. Et es lio mi sepultura en el Monasterio de los Frayres Menores de la dita Ciudad, en la Capilla de Señores Sant Luesi, y Sant Mathia que yo obrè en dito Monasterio, y para lo qual fazer honradament, segun que a mi conviene, prendo, y rescibo de mis bienes mobles, de aquellos don antes podran ser sacados quatro mil sueldos Jaqueses, de los quales quiero que sian comprados dos panios de oro bellos, de precio de cada cinquenta florines, y apres seian $/ /^{3}$ forrados, y atoquados, y levados sobre mi cuerpo del dia de mi defunsion, y dados el uno a la Iglesia del Señor San Gil do so Parroquiano, y el otro al dito Monasterio de los Frayres Menores, do mi cuerpo mando ser enterrado; quiero empero, que si yo en mi vida comprare los ditos panios de oro, y serán trobados en casa mia, que en aquel caso sian presos aquellos, y

1 El documento es un cuadernillo impreso del siglo xVIII. En su transcripción se han seguido los siguientes criterios:

El signo \& se ha transcrito como y; i se ha transcrito como j, cuando tenía valor de consonante, al igual que $\mathrm{v}$ se ha transcrito por $\mathrm{u}$, cuando tenía valor vocálico. Se han respetado las mayúsculas y minúsculas, los signos de puntuación y los acentos que aparecían en el impreso; se han mantenido unidas solo las contracciones de artículos (de+el: dello y de+al: della) y se ha señalado el cambio de página de la siguiente manera: $/ /^{2}$. Agradezco infinitamente a la doctora Asunción Blasco toda la ayuda que me ha prestado ya que, pacientemente ha transcrito la copia del testamento medieval del notario Antón Calvo, datado en 1483, comparándola con la copia impresa del siglo XVIII. Cabe decir, que en general, la copia medieval del testamento no difiere mucho de la reproducción moderna, si bien he señalado las diferencias más significativas con una nota a pie. 
que otros no ende sian comprados. ITEM, quiero, y mando que el romanient de los ditos quatro mil sueldos, sian dados a todas las de las Ordenes de los Monasterios de la dita Ciudad, Religiosos, y Religiosas que vernan, y serán a mi defunsion, a cada uno de ellos, y de ellas doce dineros, y que recegen a Dios por mi anima. ITEM, quiero, y mando que sean dados a todos los Capellanes de la Iglesia del Señor San Gil, que serán a la dita mi defunsion, doze dineros a cada uno de ellos. ITEM, quiero, y mando que sian dados a los Retores, y Vicarios de la dicha Ciudad, y que sian a la dita mi defunsion, vint y cinco sueldos. ITEM, quiero, y mando que sia feyto mi cabo de novena el tercero dia despues que finado serè, si Domingo ó festa solemne no será, y si Domingo, y festa solemne será, que ha feyto el dito cabo de novena en el otro dia del dia sigient del dito Domingo, ó festa solemne apres de la dita mi defunsion; el qual dito cabo de novena sian el Vicario, y todos los dichos Capellanes de dita Iglesia de San Gil, y les sia dado por su treballo da quel dia, a saber es, al dito Vicario diecigueit dineros, y a cada uno de los ditos Capellanes doze dineros. ITEM, quiero, y mando que durant el tiempo de un año, yo apres que finado seré, sia lebado por mi anima oblada, y candela, y un par de brandones al dito Monasterio, y que cremen cada dia mentre una Missa se dirà, al qual Missa sia oferendada la dita oblada, y candela. ITEM, del romanient de los ditos quatro mil sueldos, lexo al Convento de los ditos Frayles Menores para una pitança, y que sian tenidos fazer dentro bueyto dias apres que finado serè, un Aniversario, diziendo Missa de Requiem cantada, y dita la Missa absuelvan sobre mi fuesa con Cruz de agua bendita, quarenta sueldos. ITEM, quiero, y mando que de los ditos quatro mil sueldos, sian dados a los Conventos de los Frayles Predicadores, de Santa Maria del Carmen, de San Agustin $/ /^{4}$ de la Merced, y de las duenias Predicaderas, Menoretas, y del Sepulchre de la Ciudad; es a saber, cada vint sueldos, y que sian tenidos cada unos en su Monasterio fazer dentro huyto dias apres que finado serè, sendos Aniversarios, diziendo Missa cantada solemnenment, y apres absuelvan teniendo Cruz, y aguabendita, con los responsos, y oraciones en Santa Matre Eclesia ordenadas. ITEM, lejo de los quatro mil sueldos, que sian vestidos diez hombres pobres, clamantes de Dios, y cinco mulleres pobres, asi mismo clamantes de Dios, y aquellos diez hombres pobres el dia de mi defunsion lleven mi cuerpo; por al qual vestir a los ditos diez hombres, y cinco mulles (SIC) clamantes de dios, quiero y mando que sian compradas tres piezas de paño pardo, o cordero ${ }^{2}$ escuro, de precio cient y vint, a cient y trenta sueldos la pieza, y les sia partido por iguales partes. ITEM, lejo de los ditos quatro mil sueldos a la obra de la Iglesia de Santa Engracia de la dita Ciudad trecientos sueldos. ITEM, dexo a la obra de Santa Maria del Puey de Barbastro, trescientos sueldos. ITEM, dexo a la obra de Santa Maria del Pueyo, de sobre Villamayor, cient sueldos. IтEM, lejo a la obra de la Iglesia de Santa Maria del Portiello de la dicha ciudad treinta sueldos. ITEM, lejo a la obra de la Iglesia de San Lazaro de la dicha Ciudad, cient sueldos, pero si yo en mi vida los ditos cient sueldos, ò mas dado avrè a la dicha obra, ó aspendidos en aquella, en aquel 
caso quiero que no le sian dados los ditos cien sueldos. ITEM, quiero, y mando que feyta la dicha mi sepultura honradamente, segun que a mi conviene, pagadas, y cumplidas las lexas, y cosas sobreditas, y cada una dellas, si alguna cosa sobrarà de los ditos quatro mil sueldos, quiero, y mando que todo aquello que sobrarà sea convertido, y dado a las obras de suso escrepitas, si por mi en mi vida feitas no serán, y si feitas serán, que sean dados por amor de Dios a pobres vergonçantes, y caso, de los ditos quatro mil sueldos no complesen a lo sobredito, quiero, mando, y ordeno que todo aquello que ende faldia, sea pagado, y cumplido de los otros bienes mios. ITEM, de los otros bienes mios ordeno ende, segunt se figue. PRIMERAMENT, quiero, y mando, y ordeno q la obra que yo comencè en el claustion del Monasterio de las Menoretas; $/ /^{5}$ que sea acabada, si yo en mi vida feita no la avré acabar, en cada uno de los cruzeros en la clau, sian fetios mis señales, y que sia perfilado el dito claustion de semblant, obra que yes la claustria de Santa Maria la Mayor. ITEM, quiero, y mando que en el Monesterio de las Predicaderas de la dita Ciudad, sia feito un çellero de buelta de rexola, cabient en aquel sixanta, o setanta metradas de cubas, y que metan las cubas que las ditas duenias tienen cerca casa de Don Jayme de Espital, y que assi mismo a mision mia seya feito en una casa del dito Monasterio un sitio, al qual sia lebada la tina que las ditas duenias tienen cerca casa del dito Don Jayme de Espital; y semblantment quiero y mando que a mision mia sian mesas las tablas de las ditas duenias tienen en el Refitorio, que yes al cabo de la casa mayor, que yes enfrent de la Iglesia del dito Monasterio, y que, y sian feitas finestras rexadas altas, por las quales el dito Refitorio, y en cara del Coro puedan, y reciban luz, y que las ditas obras hisian feitas a mision mia, segunt yes dito, caso do yo en mi vida no las hubiere feito. ITEM, lexo para la obra del dormitorio de Sant Agustin de la dita Ciudad mil sueldos Jaquesess empero que si yo en mi vida los ditos mil sueldos hi dare, o sere obra alguna en el dito dormitorio, en aquel caso quiero, y mando que los ditos mil sueldos no les sian dados, ni los Frayles del dito Monasterio por vigor del present mi Testament, ni en otra manera, no los puedan demandar. IтEM, lexo a la iglesia de Señora Santa Maria de Monserrat mil sueldos Jaqueses, de los quales quiero que sian dados a los Capellanes de dita Iglesia, y que rueguen a Dios por mi anima, la mitat; y la otra mitat de los ditos sueldos que sian para la obra de la dicha Iglesia. ITEM, quiero, y mando que sia pagado a alta Dona muller mia, su axuar con su excrei, segunt que ende so tenido, iuxta los contractos de nuestro matrimonio, del qual axuar sian dedueytos, y abatidos, si su madre pagados no me los avrá, docientos florines, los quales la dita su madre me deve dar cumplimiento del dito axuar. ITEM, lexo a la dita alta dona muller mia, todos sus vestidos, y joyas, y el bel mas del piebrer, y la mas bella copa que yo tenga. ITEM, lexo a Florencianita mia filla, de Bellio Aznarez de Garden, y de Elvira filla mia $/{ }^{6}$ que fue, cinco mil sueldos, los quales yo como Tutor de Migolico y de la dita Florentica nietos mios, recibie de aquellos quince mil sueldos que yo die de axuar a la dita filla mia, y el dito Bellio le firmô, por razon del dito su axuar. ITEM, quiero, y mando que a otra part sia dado, y pagado a la dita Florentica todo aquello que se trobará con verdad yo aver recibido de las pensio- 
nes de aquellos huicientos sueldos censales, que el dito Bellio Aznarez, y D. Sancho Aznarez de Garden, hermano suyo, vendieron a mi, assi como Tutor sobredito, por razon de los ditos diez mil sueldos restantes del axuar de la dita Elvira filla mia; empero quiero que por aquesto non sia feito perjuizio alguno a los Vinculos que yo fezet mis a la dita filla mia, en el axuar que le die con el dito Bellio Aznarez, de tal manera, que si la dita Florentica finara sines de fillos legimitimos, y de legitimo matrimonio procreados, lo que Dios mande [SIC], que de los ditos quince mil sueldos sian comprados treudos perpetuos para sustentacion de pobres, y huerfanas casar, y dar a vegonçantes, segunt que de part de suso ende ordenare. ITEM, quiero que sian dados a Aznar de Corbes, y a los fillos de Pedro Lopez del Espital dos mil sueldos, en satisfacion de algunos vestidos, y joyas que yo vendie, que fueron de Elvira Lopez de Corbes $^{3}$ primera muller mia que fue. ITEM, lexo a los herederos de Marco Coscollan, o aquellos que por êl les combenrá mil sueldos, los quales mi Padre, que Dios perdone, mandó que le fuessen dados. ITEM, quiero y mando que sian dados, y pagados a los hombres del Concello de Alcañiz seiscientos sueldos. ITEM; dexo a Juanica filla de Pedro Darchaut, y de Olalia, en satisfacion del servicio que feyto me ha, y para ayuda de su casamiento quatrocientos sueldos. ITEM, dexo a Antonica, filla de Juan de la Figuera, por satisfacion del servicio que feyto me ha, quatrocientos sueldos Jaqueses. ITEM, lexo a Paschalica filla de Pedro Valero, por satisfacion del servicio que feyto me ha, y para ayuda de su casamiento quatrocientos sueldos Jaqueses; empero en tal manera, y condicion lexo a las ditas mozas, y a cada una dellas los ditos quatrocientos sueldos, que se tengan por pagadas, y que no puedan demandar otra soldada, o paga del servicio que feyto me han, o ê encaragra// $/ 7$ que si yo a ellas ó aqual quiere dellas en mi vida se les paguare, que otra vegada no las puedan demandar aquella, o aquellas a quien en mi vida los pagare. ITEM; lexo a Olalia muller de Pedro Darchaut, ducientos sueldos Jaqueses. ITEM, lexo a Todica filla de Pedro de Puertoles, para ayuda de su casamiento, û de entrar en Orden, trescientos sueldos. ITEM, lexo a Francisca Clavera, que fue algun tiempo de casa mia, por satisfacion del servicio que me fizo cincientos sueldos, y que otra soldada o paga no pueda demandar y si lo fará revoco, y quiero que no le sian dados los ditos cincientos sueldos. ITEM, lexo a Juan de la Cueba, que le sia pagada su soldada del tiempo que pagada no le será, y ultra aquello lexole de gracia ducientos sueldos, para que sia tenido fazerse unas ropas de pañie prieto al tiempo de mi fin. ITEM, quiero que sia pagado a Nicolau de Alcorisa Capellán, aquello que se trobará que yo le deva dar aquellos ducientos sueldos, que en cada un año le donava, la tabla que le tengo, y ultra aquello lexole de gracia ducientos sueldos para que sia tenido vestirse de prieto al tiempo de mi fin, y quiero que celebre una de aquellas Capellanias que entiendo lexar, y ordenar en la Iglesia de Sant Gil, si celebrar la querrá, y que reciba en cada un anio aquel salario que por mihi será asignado; y empero non teniendo publicament manceba, ô concupina, ni aviendo otro Beneficio, ni cele- 
brando por otro alguno. ITEM; lexo a Nicolau Escudero de casa mia, que le sia pagado aquello se trobará que le seia yo tenido dar de su soldada, y si al tiempo de fin en casa mia será, lexole de gracia special cient sueldos. ITEM, lexo a Martinet mozo de labor, que le sia pagado aquello que por su sagrament adverará que le sia devido de su soldada, y ultra aquello lexole de gracia dutientos sueldos, y que se vista de prieto al tiempo de mi fin. ITEM, lexo a Jayma madre de Juan Serrano, si de dias me sobrará, y sino que sian dados al dito fillo suyo, cient sueldos. ITEM, dexo a Juanico fillo de Pedro Darchaut, ${ }^{4}$ por satisfacion del servicio que feito me ha cien sueldos. ITEM, lexo a Perico por satisfacion del servicio que feito me ha, cient sueldos. ITEM; lexo a Sancho Herla, y a Matea muller suya, cient, sueldos. ITEM; es guardant a Dios, y por intuito de $/{ }^{8}$ piedad, y encara de gracia lexo a Margalitica filla mia natural para ayuda de su casamiento, los quales le sian dados cada que ella casará, y casado con voluntad de los honrados Don Iuan Ximenez Cerdan, Justicia de Aragón, Doña Maria Sanchez de Aliaga, madre del dito Justicia, Mastre Juan Castel, Retor de Mora, Don Pedro Palomar, Doña Giralda Azquerro, Juan Ximenez de Valconcha, y Juan de Capiella, ó la mayor parte de ellos, si vivos serán, vint mil sueldos Jaqueses, en tal manera empero, que si ella non casará a voluntad de los sobreditos, ó la mayor partida dellos, segun ies dito, o finará sines de fillos legitimos, y de legitimo matrimonio procreados; y assi mismo, si los fillos legitimos della finarán sines de fillos legitimos, y de legitimo matrimonio procreados, lo que Dios no mande, que en los ditos casos, y cada uno de ellos, quiero, y mando que los ditos vint mil sueldos, que a la ditta filla mia lexo, sian comprados treudos perpetuos para sustentacion de los pobres, huerfanas casar, dar a pobres vergonçantes, y otras cosas segunt, que por mi de part de suso será ordenados quiero empero, que la dita Margalita filla mia pueda ordenar de los ditos vint mil sueldos por su anima, entro á quantita de tres mil sueldos. ITEM; lexo, quiero, y mando que sian dados de mis bienes a Sancho Perez de Pila, Notario, en todo el tiempo de su vida, para sustentacion de su estamito, ducientos sueldos Jaqueses en cada un año, y no más. ITEM; lexo, quiero, y mando que sian dados de mis bienes a Juan de la Figuera en todo el tiempo de su vida, en cada un año ducientos sueldos Jaqueses; en tal manera empero, que lohe, y otorgue el presente Instrument, y ordinacion y contra aquel, y aquella no faga ni utenga en algun tiempo, y si lo fazia que no le sian dados los ditos ducientos sueldos en algun tiempo, ante quiero que los pierda en semble los quatrocientos sueldos que le dexo de part de suso a su filla. ITEM, lexo de gracia, que sean dados a Eximeno Doyna, Notario, y que se vista de prieto al tiempo de mi fin, ducientos sueldos. ITEM; lexo a Manuel de Monçon, por satisfacion del servicio que feito me ha, quatrocientos sueldos Jaqueses, y que se vista de prieto al tiempo de mi fin. ITEM; lexo Francisco Crespo, por satisfaccion del servicio/ $/{ }^{9}$ que feito me ha, aquellos mil y cincientos sueldos, que el dito Francisco, yes tenido dar a mi con carta, y quiero que no se sian demandados en algun tiempo. ITEM, quiero, y mando que sian trasladados de la Claus- 
tra del dito Monasterio de los Frayres Menores a la Capilla sobredita, do mi cuerpo mando ser soterrado, los huesos de mi Padre, y de mi madre, y que sian puestos en un baset fermoso a la part dreyta del Altar de la dita Capilla, y que sian feitos en el dito baset los seniales del dito Padre mio, y mios ITEM, quiero, y mando y assi mismo sian trasladado de la dita Claustra, y adveintos a la dicha Capilla, los huesos de Maria Sanchez de Capiella hermana mia, y sian puestos en el otro baset fermoso a mano esquierda del Altar de la dita Capilla, y sian feitos en el dito baset los seniales del dito Padre mio, y mios, y sia ancara escripto en el dito baset de letras formadas: A qui jacen, o son los huesos de Maria Sanchez de Capiella, filla de D. Juan de Capiella que fueron, por el anima de la qual, los Frayres del dito Monesterio son tenidos fazer cantar cada un año dos Capellanias en el dito Monesterio. ITEM; a reverencia, y honor de nuestro Señor, y de la Virgen Gloriosa Santa Maria, y de Señor San Gil, del qual el dito Padre mio, y yo somos seidos Parroquianos, y encara a reverencia de toda la Cort Celestial, y de si por la salud, y refrigerio de las animas de los ditos Padre, madre, y hermanos mios, y de mi anima, y de las animas de mis mulleres, fillos, y de todos los otros ascendentes de mi; ordeno, siquiere instituezco dos Capellanias perpetuas, de cada cincientos sueldos, celebraderas en la Iglesia, y Altares del Señor Sant Gil, y de Santa Maria de la dita Iglesia, en qualquiere de aquellos; en las quales Capellanias, y alguna dellas, el Papa Legado, Vicario suyo, Cardenal, el Arcebispe de Zaragoça, su Oficial, ni persona otra alguna Eclesiastica, ô Seglar, por via de rediezmo, visitación, subsidio, synodo, racha, aguncion, ${ }^{5}$ ni el alguna otra manera, que dezir, pensar, o congitar se pueda, no puedan aver dreyto, ni imponer carga alguna, ni se puedan de aquellas, y de algunas dellas en alguna manera entremeter, sino aquel y aquellos aqui por mi de part de suso ende sia dado, o comendado $/ /^{10}$ poder y a sustencacion de las quales Capellanias, y por salario, ó charidad de los Capellanes que aquellas celebrarán, lexo, y asigno mil sueldos Jaqueses; es a saber, aquellos cincientos sueldos Jaqueses de cens, siquiere treudo perpetuo en cada un año, que los hombres del Concello, e Universidad de la Villa de Alquezar vendieron, y fecieron vendicion al honrado Mastre Juan Castel, Retor de Mora, pagaderos en cada un año en el quinceno dia del mes de Abril dia a diado dentro en Zaragoça con ciertas penas, ostajes, y obligaciones contenidas en el contracto de la dita vendicion, el qual fue feito en la dita Villa de Alquezar, a nueve dias del mes de Março, anno á Nativitate Dominini millesimo trecentesimo octavag simo, por Jayme Perez de Burgos, habitante en Zaragoça, por autoridad del Señor Rey Notario publico por toda su Tierra, y Señorio, y de los quales cincientos sueldos censales, el dito Maestre Juan Castel, fizo cession, y donacion a mi dito Miguel Capiella, con ciertos vinculos, y condiciones contenidas en la dita donacion, la qual fue feita en Zaragoça a diez y hueito dias de Mayo, anno á Nativitate Domini millesimo trecentesimo octvagesimo quarto por Sancho Martinez de la Peyra Notario publico de la Ciudad de Zaracoça, dius scripto. ITEM, aquellos cincientos sueldos Ja- 
queses de cens, siquiere treudo perpetuo en cada un anio que yo he, y los hombres del Concello, siquiere Universidad de la Villa de Magallon fazen y son tenidos fazer a mi dito Don Miguel de Capiella, con ciertas penas, ostajes y obligaciones contenidas en el contracto de la vendicion del dito censal; y de los cuales mil sueldos ditos censales, siquiere treudos perpetuos en cada un anio, quiero, y mando que ayan, y reciban los Capellanes que las ditas Capellanias celebrarán, por salario, siquiere caridad en cada un anio cada cincientos sueldos Jaqueses; a saber ies, docientos y cinquenta sueldos cada uno dellos, en los plazos, y tiempos que justa los contractos de las ditas vendiciones se deven pagar; y por los quales cada cincientos sueldos, los ditos Capellanes, y cada uno dellos sian tenidos cada un día celebrar en la dita Iglesia de Señor Sant Gil, y en los ditos $/ /^{11}$ Altares, o qualquiere dellos, y fazer oracion, y comemoracion special por las animas de los sobreditos y mia; y ditas las Missas debant de los ditos Altares, ó qualquiere dellos, con Cruz, y aqua benedita sian tenidos fazer, y fagan cada dos absoluciones diziendo los responsos, y oraciones en la Santa Madre Iglesia ordenados, y encara que los ditos Capellanes, y cada uno de ellos sian tenidos servir, y fier en la dita Iglesia de Sant Gil, a Missa Mayor, y Viespras todos los Domingos, dias de Pasqua, de Santa Maria y de las otras Festividades solemnes, que la Iglesia manda tener, y honrara ó é encara de todas las Festividades que aya Altares, y advocaciones en la dita Iglesia de Sant, Gil; y que assi mesmo, los ditos Capellanes, y cada uno dellos, sian tenidos fer con las sobrepellizes a las defunsiones de los difuntos pobres, que la Confraria de Santa Fè y los Confrayres de aquella por amor de Dios, con los bienes de la dita Confraria entierran, sines de salario alguno que no sia dado a alguno de los ditos Capellanes, o è encara ò si los ditos Capellanes, ô alguno dellos fallirán en celebrar las dichas Capellanias, ô alguna de aquellas, y assi mesmo si fallirán en el servicio que fazer deven las Festividades de la dita Iglesia, o del enterrar de los difuntos de por Dios, que los Confrayres de la dita Confraria de Santa Fe, segun yes dito farán soterrar, paguen, y sian tenidos pagar por las faltas de cada una dellas, Missas que fallirán, y non celebrarán, doze dineros cada uno dellos, y por la falta de cada una Festividad, y cada uno de los ditos difuntos pobres seis dineros, los ditos difunto, y difuntos se enterrarán; y que las ditas penas paguen y sian tenidos pagar, y le sian deminuidas del salario sobredito, que las ditas Capellanias recibirán, al Vicario que ies, o por tiempo será de la dita Iglesia, si doneas los ditos Capellanes, ô qualquiere dellos iuxta escusacion no avrán conocimiento del dicho Vicario, assi del dezir, y celebrar de las ditas Missas, como de los otros servicios sobreditos que fazer devensy que el dito Vicario parta, y destribuezca, y sia tenido partir, y destribuir las ditas penas, y cada una dellas a los pobres $/ /^{12}$ clamantes de Dios, en remission de los pecados de las animas de los sobreditos, y mia y de aquestos ende en cargo el anima del dito Vicario; y si por aventura de los ditos Capellanes, ó alguno dellos recusarán, y no querrán pagar las ditas penas, y fazer el dito servicio, assi en el celebrar la ditas Capellanias, y cada una dellas, como en ser los Domingos, y Festividades solemnes en la dita Iglesia, y enterrar los difuntos pobres de Santa Fé, en los ditos casos, y cada uno 
dellos, quiero, y mando que aquel, y aquellos que contrastarán pagar las ditas penas, y de fazer el dito servicio, segunt, de suso ies ordenado, que les sian tirada, y tiradas las ditas Capellania y Capellanias por los Patrones dius scriptos, y dadas a otro y a otros que las celebren, y sirvan en la forma, y con las condiciones sobreditas, y dius scriptas. ITEM, quiero, y mando, y ordeno que las ditas Capellanias sia Capellan y celebre la una de aquellas, si al tiempo de mi fin vivo será, y la querrá celebrar el dito Nicolau de Alcorisa, y aya por salario, ó charidad de aquella en cada un anio los ditos cincientos sueldos, en la forma, y manera sobredita, y segunt ies de suso ordenado, y contenido, y el empero no aviendo otro Beneficio, ni teniendo publicament manceba ó concupina, segunt ies dito; y la otra de las ditas Capellanias, quiero que sea celebrada por Capellan unio parient, y el mas cercano de part de Padre si ordenado será; y si parient mio de part de mi Padre ordenado no será, que sia celebrada por parien mio el mas cercano de part de mi madre que trobado será, no aviendo otro Beneficio, ni tenido publicament manceba, o concupina, segunt ies dito; y ende fallimiento del dito Nicolau de Alcorisa, y de parientes mios Capellanes de part de mi Padre, y de mi madre, quiero, y mando que sian celebradas por dos Capellanes los más idoneos, y suficientes, no habientes otros Beneficios, ni teniendo manceba, ó concupina publicament, que los Patrones de mi de part de suso lexados, y ordenados trobarán, y aver podrán; y que los ditos Capellanes, y cada uno dellos, de que las ditas capellanias, y cada una dellas, por los ditos Patrones dadas les serán, celebren, y sian tenidos $/ /^{13} \mathrm{ce}$ lebrar aquellas, y fagan, y sian tenidos fayer los sobreditos servicios, iuxta, y segun que ies por mi de part de suso ordenado, y mandado; y reciban; y ayan, los ditos mil sueldos de los ditos censales, y cada uno dellos por iguales partes, en los terminos, siquiere plazos que pagar se devan, y ayan, y les doy poder de fazer ende Albaran, y Albaranes de aquellos en cada un anio, en las tandas, y terminos que los reciban; empero si alguno, ó algunos de los ditos Capellanes fallirán, farán o venirán en alguna cosa contra la dita mi Institucion, y Ordinacion de las ditas Capellanias, y cualquiere dellas, y del dito salario, ó caridad, y que por los ditos Patrones les sian tiradas, y dadas a otro, ó otros Capellanes, idoneos, y suficientes, que aquellas celebren, y sirvan, segunt de suso ies dito, contenido, y expressado. ITEM; lexo, y asigno Patrones de las ditas Capellanias, y cada una dellas, y los quales apres dias mios, dentro de un mes despues que finado seré, y de allí adelant, cada y quando las ditas Capellanias, o qualquiere de aquellas, por muerte de los ditos Capellanes, ó qualquiere dellos, o en otra qualquiere manera vacarán, dentro de un mes dent, y sian tenidos dar las ditas Capellanias, y cada una dellas; y que en aquello el Papa Vicario, ó Legado suyo Cardenal, el Arçobispo de Zaragoça, su Oficial, ni otra persona alguna, y Eclesiastica, o Seglar, no les puedan entremeter embarg, ó contraste alguno, ni se puedan tremeter de dar las ditas Capellanias, ni alguna dellas por via de gracia, impetracion, assuncion, ${ }^{6}$ ni en 
alguna otra manera, sino tan solament los Patrones dius scriptos, y que se siguen. ${ }^{7}$ Es a saber, al heredero mio si de perfecta edad será, y entrotanto que el dito heredero mio de perfecta edad será, a Juan de Capiella, Notario publico de la Ciudad de Zaragoza, y cada que el dito heredero mio de perfecta edad será, que torne al dito el dito Patronado, y a los descendientes de reta linia de aquel; y ende fallimiento de dito mi heredero, y de los descendientes de recta linia de aquel, que torne el dito Patronado al parient mas cercano mio de part de mi Padre, si apto, y suficient trobado será, y a los descendientes de recta linia de aquel; y ende fallicimient $/ /{ }^{14}$ de parientes aptos, y suficientes de part de mi Padre, y de los descendientes de recta linia de aquel, que el dito Patronado torne al parient mas cercano mio de part de mi madre, si apto, y suficient trobado será, y a los descendientes de recta linia de aquel; y ende fallecimient de parientes aptos, y suficientes de parte de mi Padre, y de mi madre, y de los descendientes de recta linia de aquellos, que el dito Patronado torne al Vicario de la dita Iglesia de Sant Gil, con uno de los Mayordomnes de la dita Confraria de Santa Fè, y de la Iglesia de Sant Gil, que por tiempo serán, ó Deputado en lugar del dito Mayordomo por el Capitulo de los Confrayres de la dita Confraria de Santa Fe en el dito Vicario ensemble, a los quales Patrones a cada uno dellos en su tiempo y caso, do pleno, y bastant poder de dar Capellan, y Capellanes a las ditas Capellanias, y cada una dellas por si, y por su propia autoridad, menos de licencia, mandamiento, ó conocimiento de alguna otra persona Eclesiastica, ô Seglar, en la forma, y con las condiciones sobreditas, y cada una dellas. ITEM; a servicio, honor, y reverencia de nuestro Señor Dios, y de la Virgen Señora Santa María, y de Señor Sant Gil, y de Señora Santa Fè, y de toda la Cort Celestial; y por salud, y refrigerio de las animas de mi Padre, de mi madre, y de mi hermana, y mia, y de las animas de mis mulleres, de mis fillos, de mis hermanos, y de los otros fieles difuntos mios antepassados, quiero y mando, y ordeno que cada un dia, à perpetuo, apres que finado seré, sian proveidos treze pobres clamantes de Dios en el Espital de Santa Fè de la dita Parrochia de Sant Gil, por el Vicario de la dita Iglesia, y por aquel Confrayre que en lugar del dito Mayordomo el Capitulo de los Confrayres de la dita Confraria hi deputará, y ordenará en semble en el dito Vicario, de los quales pobres sian hueyto hombres, y cinco mulleres, y que sian personas flacas, y debelitadas, que no ayan de la sustancia deste mundo, ni podientes lo treballar, o ganar, a conocimiento de los Vicario, y Mayordomne, o Deputado a aquello por el Capitol de los Confrayres//15 de la dita Confraria, y esto por tal que mayor merito, y relebamiento sia a las animas de los sobreditos, y mia; y a los quales pobres, y pobras quiero, y mando que les sian dados por razon de la dita provision cada un dia seis dineros, y montan en un anio toda la provision de los ditos treze pobres dos mil trecientos setenta y dos sueldos seis dineros; y para la dita quantia á perpetuo cumplir, y pagar, etxo y en otro atanto que por mi, ó por aquellos aqui por mi por el present Testament mio ende será dado poder y carga, sian comprados treudos perpetuos entro

7 En la copia del notario Antón Calvo: «signen». 
a la dita quantia de dos mil trecientos setenta y dos sueldos seis dineros de la dita provisission, lexo y assigno todos, y cada unos treudos, y logueros, que yo he; y se trobarán en la dita Ciudad de Zaragoça, y en los terminos de aquella, que yo he costumbrado aver, pretender, y recibir, excepto el Molino de olio mío, y de las casas, y huertos de la tenencia de aquel. ITEM, mas lexo, y assigno para la paga de los ditos dos mil trecientos setenta y dos sueldos, y seis dineros de la provission de los ditos pobres, aquellos huycientos huytan ta tres sueldos quatro dineros Jaqueses cens, siquiere treudo perpetuo en cada un anio, pagaderos por el huyto dia del mes de Abril, que el Procurador del Concello, siquiere Univesidad del Lugar de Calçena vendie al honrrado Juan D. Sancho Mercader, y Ciudadano de la dita Ciudad, por precio de diez mil sueldos Jaqueses, segunt parece por carta publica de la dita vendicion, feita en Zaragoça a seis dias de Abril anio á Nativitate Domini millesimo trecentesimo octuagesimo quarto, por Săcho Martinez de la Peyra, Notario publico de Zaragoça dius scripto. ITEM mas, si los ditos treudos, y logueros mios, y censal sobredito de Calçena, no cumplirán a la sobredita provission lexo, y assigno, y quiero,y mando que sia preso, y complido todo lo que fallirá de los ditos dos mil trecientos setenta y dos sueldos seis dineros de la provission de los ditos pobres; es a saber, de aquellos huycientos huytanta tres sueldos quatro dineros Jaqueses de cens, siquiere treudo perpetuo en cada un anio, $/ /{ }^{16}$ pagaderos por primero de Mayo, que los hombres del Concello, y Universidad del Lugar de Belchit de la Partida del Alto Señor Infant D. Martin, agora Duch de Monblanc, vendieron al dito Johan D. Sancho, por precio de diez mil sueldos, Jaqueses, segunt parece por carta publica de la dita vendicion, feyta en dicho Lugar de Belchit vint y nueve dias de Abril anno à Nativitate Domini millesimi trecentesimi octuagesimo quarto por el dito, y dius scripto Sancho Martinez de la Peyra Notario; y de los quales censales, assi del dito Lugar de Calçena, como del dito Lugar de Belchit de la Partida del dito Senior Duch y de otros el dito Johan D. Sancho fizo cession, y donacion, con ciertos vinculos, y condiciones a mi dito Don Miguel de Capiella, segunt parece por carta publica de la dita donacion, feyta en la Villa de Alchaniz el primero dia de Julio anno à Nativitate Domini millesimo trecentesimo octuagesimo quarto, por el dito, y dius scripto Sancho Martinez de la Peyra Notario; de los quales treudos logueros, y censales quiero, mando, y ordendo que sian presos, y recibidos, y do poder de prender, y recibir, y fazer Albaranes de aquello, a los ditos Vicario, y Mayordomne, al Deputado que por el Capitol de la dita Confraria de Santa Fè serà en semble con el dito Vicario en cada un anio, los ditos dos mil trecientos setenta y dos sueldos seis dineros de la provisión de los ditos pobres; y por los ditos Vicario, y Mayordomne, ò Deputado en lugar del dito Mayordomne, con el dito Vicaro en semble, sian destribuidos a los ditos pobres cada un dia dandoles seis dineros de provission, segunt dito ies, tanto y tan largament entro que los ditos treudos perpetuos sian comprados entro cumplimiento de los ditos dos mil trecientos setenta y dos sueldos seis dineros de la provission de cada un anio de los ditos pobres, segunt ies dito; y pagados, y cumplidos en cada un anio los ditos dos mil trecientos setenta y dos sueldos seis 
dineros de la provission de los ditos pobres, lo que sobre de los ditos treudos logueros, y censales, y cada uno dellos, quiero, mando, y ordeno que sia pagado, y cumplido en cada un anio aquello que por mi de $/ /^{17}$ part de suso ende serà mandado, y ordenado, tanto y tan largament entro que semblantment sian comprados treudos perpetuos para aquella cnmplir (SIC) y pagar, y cada y quando siràn los ditos treudos perpetuos comprados para cumplir, y pagar, assi los ditos dos mil trecientos setenta y dos sueldos seis dineros de la provission de cada un anio de los ditos pobres, como para cumplir y pagar, las otras cosas que de part de suso assignarè, y mandarè pagar de los ditos treudos logueros, y censales de Calçena, y de Belchit, quiero, y mando que los ditos treudos logueros, y cada uno dellos sian, y finque francament, y quiet al heredero mio, ô adaquel, ò aquellos que yo de nuestro Señor Dios, y Señora Santa Maria, y de toda la Cort Celestial, y a salud, y refrigerio de las animas de los sobreditos, y mia, quiero, mando, y ordeno que en cada un anio a perpetuo sian dados, y destribuidos por los ditos Vicario de la Iglesia de Sant Gil, y uno de los Mayordomnes, ò Deputado por el Capitulo de los Confrayres de dita Confrayria de Santa Fê, con el dito Vicario en semble, mil sueldos Jaqueses en cada un anio en casar huerfanas, dando, y destribuyendo aquellos a huerfanas pobras que lo ayan menester para ayuda de sus casaminetos, a cada una ducientos sueldos; empero, quiero, y mando que si parientas mias avrá pobras, que lo ayan menester, a conocmiento del dito Vicario, y Mayordomne, ò Deputado por el Capitulo de la dita Confraria de Santa Fè, que aquellas parientas mias pobras, sian preferidas a todas la otras, y les sian dados siendo parientas mias, segun ies dito, en ayuda de sus casamientos cada cicientos sueldos Jaqueses, y el dito parentesco de aquellas, y mios, se entienda entro el cinqueno grado; ò ê encara quiero, y mando que sian compressas, y se entiendan en el dito mi parentesco las fillas de Pedro de Puertoles, la filla del dito Pedro Valero; y si parientas mias no fei trobrán cercanas dentro el cinqueno grado, que los ditos mil sueldos en cada un anio sian destribuidos por los sobreditos, a otras huerfanas casar, dandoles en ayudas de sus matrimonios los ditos $/ /^{18}$ docientos sueldos; empero si algunas donzellas se he trobará vergonçantes pobras, y lo avrán menester, que los ditos Vicario, y Mayordomne, ò Deputado con dito Vicario en semble, notificandole primero al Capitol de los Confrayres de la dita Confrayria de Santa Fè, y faziendolo con su conciencia, lo puedan disponer, y dar mas adaquellas donzellas pobras vengonçantes para ayuda de sus matrimonios, segunt que en sus conciencias, verán, y conocerán que se les deva de los ditos mil sueldos dar para ayuda de los ditos sus casamientos, segun ies dito; y para sustentacion, y paga de los ditos mil sueldos, en el entrotanto que por mi, y por aquellos que por mi por el present Testament ende será dado cargo, sian comprados treudos perpetuos ento a quantia de los ditos mil sueldos de la dita destribucion del casamiento de las ditas huerfanas, lexo y assigno aquellos cincientos sueldos Jaqueses de cens, si quiere treudo perpetuo en cada un anio, que los hombres del Concello y Universidad del Lugar de Lezera vendieron al dito Juan D. Sancho, pagaderos, por el diciseteno dia del mes de Janero, por precio de seis mil sueldos, segunt parece por carta publica de la dita 
vendicion, feyta en el dito Lugar de Lezera diez y siete dias de Janero anno à Nativitate Domini millesimo trecentesimo octuagesimo quarto, por el dito y dius scripto Sancho Martinez de la Peyra Notario, y de los quales el dito D. Sancho fizo cession, y donacion a mi dito Don Miguel de Capiella, segunt parece por carta publica de la dita donacion, feyta en la dita Villa de Alcañiz el primero dia de Julio, anno à Nativitate Domini millesimo trecentesimo octuagesimo quarto, por el dito y dius scripto Sancho Martinez de la Peyra Notario. ITEM mas, aquellos cincientos sueldos de cens, siquiere treudo perpetuo en cada un anio, que los hombres del Concello, siquiere Univeridad de la Villa de Fraga fazen, y son tenidos fazer, siquiere pagar a mi dito Don Miguel de Capiella, dius scriptas penas, ostajes, obligacions, y condiciones contenidas en el contracto de la vendicion del dito censal; y que los ditos Vicario, y Mayordomne por el Capitol de los Confrayres de $/ /{ }^{19}$ la Confraria de Santa Fè, con el dito Vicario en semble, ayan, y reciban los ditos mil sueldos de los ditos censales, y cada uno dellos, y ende fagan albaran, y los destribuezcan en cada un anio en casar las ditas huerfanas en la forma sobredita, tanto y tan largament que por mi, y por aquellos aqui por el present mi Testament ende serà dado cargo, è poder, sian comprados treudos perpetuos entro a quantia de los ditos mil sueldos, para distribucion de casar huerfanas en cada un anio, segun ies dito; y cada, y quando por mi, ô por aquel, ó aquellos aqui por el present mi Testament en dare poder, serán comprados treudos perpetuos entro a quantia de mil sueldos, para destribucion en cada un anio de las ditas huerfanas casar, segun ies dito, que los ditos censales de Lezera, y de Fraga, y cada uno dellos, sian y finque a mi heredero, ò adaquel, ô aquellos que yo querré, ordenarê, y mandarè por el present mi Testament. ITEM, encara a honor, reverencia, y servicio de nuestro Señor Dios, y de toda la Cort Celestial; y assi mesmo por salud, y refrigerio de las animas de los sobreditos, y mia, quiero, mando y ordeno que en cada un anio perpetuament sian dados, y destribuidos por los ditos Vicario, y uno de los Mayordomnes de la dita Confraria de Santa Fè, ò por el Deputado en el lugar del Mayordomne por el Capitol de los Confrayres de la dita Confrayria, en semble con el dito Vicario, en cada un anio a pobres vegonçantes mil sueldos Jaqueses; empero quiero, y mando que si parient, ò parientes mios cercanos en parentesco a mi entro cinqueno grado seră vergõçantes, y lo avrán menester, que toda via catando primero el mas cercano en grado, que mas menester lo avrá, que sia dado a cada uno dellos, y que a otra mayor vergona no aya venir, es a saber docientos sueldos Jaqueses a cada uno dellos en cada un anio, si tantos ende avrá; quiero empero, que de los ditos mil sueldos sian dados primerament en cada un anio al dito Joanico, fillo de los ditos Pedro Darchaut, y Olalia, para aprender, cient y cinquenta sueldos, y esto entro atanto que sia de edad de vint y dos anios; y a la dita Olalia en todo el tiempo de su vida cient sueldos y lo que $/ /^{20}$ romandrá sia partido a parientes mios vergonçantes cada un anio, segunt ies dito; y si parientes mios vergoncantes noy avia, quiero que sia dado, y destribuido a otros pobres vergonçantes, dando en cada un anio a cada uno dellos cient suedos QUIERO, y mando empero, que si tales pobres vergonçantes hi avrá que lo huviessen gran menester, que los ditos Vica- 
rio, y Mayordomne, ò Deputado en lugar del dito Mayordomne, con el dito Vicario en semble, segunt ies dito, lo puedan suplir, y darle mas de los ditos cient sueldos, notificandolo primero, y faziendolo a saber al Capitol de los Confrayres de la dita Confraria de Santa Fè. ASSI empero, quiero, y mando que el Vicario de la dita Iglesia de Sant Gil, y el uno de los ditos Mayordomnes, ò Deputado en lugar del Mayordomne dito a los sobredito con el dito Vicario fazer, segunt ies dito, como en los ditos Oficios en cada un anio los esleyràn, y meteràn, $\mathrm{y}$ ante que en res de lo sobredito usaràn, juren, y sian tenidos jurar en poder del Capitol de los Confrayres de la dita Confraria de Santa Fè, û de uno de los Confrayres que el dito Capitulo será, sobre la Cruz, y Santos quatro Evangelios de nuestro Señor Jesu Christo, por cada uno dellos manualmente tocados, y assi en el Patronado de las ditas Capellanias, como en las destribuciones de la provission de los ditos pobres, casar de huerfanas, y de los ditos vergonçantes, y de cada unos dellos, y dellas, y de todas las otras cosas que por mi en el present Testament les seràn comendadas, aver, y lebarse bien fielment, iuxta y segun mi intencion, y ordinacion sobredita, toda afeccion, parcilidad, y voluntad desordenada, tiradas, y removidas, y para pago siquiere sustentacion a perpetuo cumplir los ditos mil sueldos de la destribucion en cada un anio a los ditos vengonçantes, fazedera segunt ies dito, y entro atanto que por mi, ò por aquellos que yo ordenare, y mandare por el present mi Testament sian comprados treudos perpetuos, en la dita quantia de mil sueldos de la dita destibucion, lexo, y assigno aquellos cincientos sueldos Jaqueses de cens, siquiere treudo perpetuo en cada un anio, que los hombres del Concello siquiere//21 Alxama de Letux fazen y son tenidos fazer a mi dito Don Miguel Capiella en cada un anio, segunt ies dito, dius ciertas penas, ostajes, y obligaciones contenidas en el contracto de la vendicion del dito censal. ITEM mas, cincientos sueldos Jaqueses, de aquellos seiscientos sueldos Jaqueses de cens, siquiere treudo perpetuo en cada un anio, que los hombres del Concello, y Universidad del Lugar de Belchit de la Partida del Noble Don Pedro Maza, fazen, y son tenidos fazer en cada un anio, segunt ies dito, a mi dito Don Miguel de Capiella, dius ciertas scriptas penas, ostajes, y obligaciones contenidas en el contracto de la vendicion del dito censal, siquiere empero que cada, y quando por mi, ò por aquel, ò aquellos aqui por el present Testament en dare poder, serán comprados treudos perpetuos en quantia de mil sueldos de la destribucion de los ditos vergonçantes en cada un anio, que los ditos censales de Letux, y de Belchit de la Partida del dito Noble Don Pedro Maza, y cada uno dellos, sian, y finque a mi heredero, ò aquel ó aquellos que yo querrè, mandarè, y ordenarè por el present mi Testament, segunt ies dito. ITEM, encara por salud, y refrigerio de las animas de los sobreditos Padre, madre, hermanos, mulleres, y fillos mios, y de mi anima, y de todos los otros fieles difuntos, que yo sia tenido, segunt ies dito, instituezco, y ordeno doze Aniversarios de cada diez sueldos perpetualment, y a todos tiempos en cada un anio, celebraderos, y fazereros en la dita Iglesia de Señor Sant Gil, por el Vicario, Cabiscol, y hueyto Capellanes de los perpetuos en dita Iglesia de Sant Gil, si tantos idi avrá, y sino que hisian puestos entro en dito numero del hueyto Capellanes anuos de los ditos Vicario, y 
Cabiscol, de los otros Capellanes que seràn en la dita Iglesia; pero quiero que los ditos dos Capellanes, que las ditas mis Capellanias celebrarán, sian todavia entendidos, y compresos en el numero de los ditos hueyto Capellanes, y que en cada un mes de cada un anio sia feyto, y celebrado uno de ditos Aniversarios, diziendo Misa de Requien alta, y dita la Missa con Cruz, y agua bendita, tocando las campanas, y cantados dos responsos//22 de la dita Iglesia, sagan dos absoluciones por las animas de los sobreditos, y mia; y feyto en cada un mes un Aniversario, segunt ies dito, quiero, y mando que ayan de destribucion por cada uno de los Aniversarios ditos, en cada un mes diez sueldos, y de los quales ayan, a saber ies, el dito Vicario, y celebre la Missa dos sueldos; y el dito Cabiscol, y faga tocar las campanas doze dineros, y cada uno de los hueyto Capellanes otros seis dineros, y los tres sueldos restantes a cumplimiento de los ditos diez sueldos, sia feyta oferenda de obladas, y candelas, que sian oferecidas a la dita Missa, y para sustentacion de los ditos doze Aniversarios, ô caridad de los dito Vicario, ò Capellanes, que aquellos farán, y celebraràn cada un mes, segunt ies dito, lexo, y asigno cient y vint sueldos Jaqueses del romanient, y de sus terminos, y censales del Calçena, y de Belchit de la Partida del dicho Señor Duch, ya de susso por mi dexados, y assigdos a la destribucion de los treze pobres, segunt que suso ies expressado, y contenido, destribuideros por los ditos Vicario, ò Mayordomne por el Capitol de los Confrayres de la dita Confrayiria de Santa Fè, con el dito Vicario en semble, segun ies dito, è por tal que los ditos Vicario de la dita Iglesia de Sant Gil, y Mayordomne de la dita Confrayria de Santa Fè, ò Deputado en lugar del dito Mayordomne, por el Capitol de los Confrayres de la dita Confrayria, ayan mayor, y millor cura, y deligencia de treballar, y entender cerca las pagas, y destribuciones por ellos fazederas, en la destribucion de los ditos pobres, huerfanas, vegonçantes, y Aniversarios, segunt ies dito, lexo, y assigno a los ditos Vicario, y Mayordomne, ò Deputado en lugar del dito Mayordomne, segunt ies dito, y por satisfacion de sus treballos cient sueldos Jaqueses, a saber ies, cinquenta sueldos en cada un anio al dito Vicario, y cinquenta sueldos al dito Mayordomne de la dita Confrayria de Santa Fè, ò Deputado lugar del dito Mayordomne, segunt ies dito, los quales ditos cient sueldos en cada un anio ayan, y reciban por satisfacion de sus traballos y salario, segun ies dito, tanto, y tan largament//23 entro que sian feytas compras de treudos perpetuos entro a la dita quantia de cient sueldos de salario, ò pension de los ditos Vicario, y Mayordomne, segunt ies dito, a saber ies, en y de lo que romandrá de los treudos, y logueros mios de Zaragoça, y sus terminos, y censales de Calçena, y de Belchit de la Partida del dito Señor Duch, de la parte de suso por mi a la provisision de los ditos treze pobres de cada, un anio asignados, segunt ies dito, assi, y en tal manera, que quiero, y mando, y ordeno que por los dito Vicario de Sant Gil, y Mayordomne que por tiempo serà de la dita Confraria de Santa Fè, ò por el Deputado en lugar del dito Mayordomne por el Capitol de los Confrayres de la dita Cofrayria en cada un anio serà, con el dito Vicario en semble, en cada un anio apres de dias mios, ayan, y reciban, y les do poder de recibir, y fazer albaranes en cada un anio, de todos los treudos, y logueros que yo he acossumbrado 
prender, y recibir en la dita Ciudad de Zaragoça, y en los terminos de aquella, y los sobreditos censales de Calçena, y Belchit de la Partida del dito Señor Duch y de Lezera, de Letux, y de Fraga, y encara de Belchit en la Partidad del dicho Noble Don Pedro Maza, y cada unos dellos, y de fazer, y fagan en cada un anio las pagas, y destribuciones sobreditas, y cada una dellas, segunt, y en la forma que de susos ies por mi mandado, y ordenado, tanto, y tan largament entro que por mi ò por aquel, ò aquellos que por mi serà mandado, $\mathrm{y}$ ordenado sian comprados treudos perpetuos cumplientes, y bastantes a las pagas, siquiere destribuciones sobreditas, y cada una dellas, y por mi feytas, y asignadas a la provision de los dichos treze pobres, casar de huerfanas, dar a vegonçantes, Aniversarios, y salario de los ditos Vicario y Mayordomne, ò Deputado en lugar del dito Mayordomne, segunt ies dito; y si por aventura los treudos, y logueros que yo he en la dita Ciudad de Zaragoça, y en sus terminos, y censales de Calçena, y de Belchit, de la Partida del dito Señor Duch, no bastará, y cumplirán en cada un anio a la provission de los ditos pobres y a la paga de los doze Aniversarios, y a la paga de los cient sueldos del//24 salario de los ditos Vicario, y Mayordomne, ò Deputado en lugar del dito Mayordomne, segunt ies dito, quiero y mando, que todo aquello que endre saldrá sia preso, y cumplido de aquellos cient sueldos restantes de aquellos seiscientos sueldos, que los hombres del dito Lugar de Belchit de la Partida del dito Noble Don Pedro Maza, fazen, y son tenidos fazer a mi dito Don Miguel de Capiella en cada un anio, segunt ies dito; y de aquellos trecientos sueldos Jaqueses de cens, siquiere treudo perpetuo en cada un anio, que a los adelantados, y Aljama de los Judios de Daroca fazen, y son tenidos fazer a mi dito Don Miguel de Capiella, con ciertas penas, ostajes, y obligaciones contenidas en el contracto de la vendicion del dito censal, y pagado, y cumplido de los cient sueldos restantes de los seiscientos sueldos Jaqueses del cens, siquiere treudo perpetuo, que los hombres del Concello, siquiere Universidad del Lugar de Belchit de la Partida del dicho Don Pedro Maza; y assi mismo de los trecientos sueldos del cens, siquiere treudo perpetuo, que los adelantados, y Aljama de los Judios de Daroca fazen, y son tenidos fazer a mi dito D. Miguel de Capiella, en cada un anio, segunt ies dito, todo lo que fallerà de los ditos dos mil trecientos setenta y dos sueldos seis dineros, de la provisiõ de cada un anio de los ditos pobres, y cient y vint sueldos del salario caridat de los ditos doze Aniversarios, y cient sueldos del salario de los ditos Vicario, Mayordomne de la dita Cofraria de Santa Fè, ò Deputado en lugar del dito Mayordomne, segunt ies dito; que todos los logueros, y treudos mios de Zaragoça, y sus terminos y censales sobreditos de Calçena, y Belchit de la Partida del dito Señor Duch, por mi de suso asignados, y lexados a las ditas destribuciones, no cumplirá, segunt ies dito, todo lo que sobre de los ditos cient sueldos restantes de los seiscientos sueldos del censal de Belchit de la Partida del dito Noble Don Pedro Maza, y de los trecientos sueldos del dito censal de la Juderia de Daroca, sian y finque a mi heredero, ò adaquel que yo querrè, mandarè; y ordenarè; y caso assi mesmo de los ditos treudos logueros, y censales por mi a las ditas destribuciones//25 y cada una dellas de susso assignadas, no y cumpliessen, quiero, y mando que todo aquello que falirà sia 
cumplido, y pagado de los otros bienes mios; quiero encara, y mando que cada, y quando por mi, ò por aquel, ô por aquellos que yo ordenare, y mandare, sian comprados treudos perpetuos bastantes a la destribuicon de los ditos dos mil trecientos setenta y dos sueldos seis dineros de la provission de los ditos treze pobres de cada un anio, y de los cient y vint sueldos del salario de los ditos doze Aniversarios, y de los cient sueldos del salario de los ditos Vicario, y Mayordomne, ó Deputado en lugar del dito Mayordomne, segunt ies dito, que los ditos treudos, y logueros mios de la dita Ciudad, y sus terminos, y los ditos Censales de Calçena, y de Belchit de entramas las Partidas, y de la Juderia de Daroca, y cada uno dellos sian, y finquen francos, quitos, y expeditos de la provission de los ditos pobres, Aniversarios, y salarios de los ditos Vicario, y Mayordomne, ô Deputado en lugar del dito Mayordomne, y de la carga de aquellos, y de cada uno de ellos, segunt ies dito; y romangt, y finque al heredero mio, ò adaquel, ô aquellos que yo querrè, ordenarè, y mandarè, segunt dito ies; y por tal que las sobredichas destribuicones, y cada una dellas fazederas en cada un anio por los ditos Vicario de Sant Gil, y Mayordomen de la dita Cofraria de Señora Santa Fè, ó Deputado en lugar del dito Mayordomne, segunt ies dito, ayan aquella diligenica, y administracion que convenga en cada un anio, iuxta el tenor de la sobredita mi ordinacion, ruego carament al Capitol de los Confrayres de la dita Cofradia de Señora Santa Fè de la dita Iglesia de Sant Gil, que cada y quando esleyràn, y meteràn Mayordomnes en la dita Confraria, ò Deputaràn uno en lugar del dito Mayordomne personas buenas, y de buena anima, y conciencia, y que el uno de los ditos Mayordomnes, ó Deputado en lugar del dito Mayordomne por el dito Capitol, con el dito Vicario en semble, juren en poder del dito Capitol sobre la Cruz, y Santos quatro Evangelios por cada uno dellos manualment $/ /^{26}$ tocados, que en el Patronado de las ditas Capellanias en su tiempo, y caso, y en las destribuicones sobreditas, y cada una dellas, se avràn, y lebaràn bien, y legalment toda afeccion parcialidad, y voluntad desordenada, tiradas, y removidas, segunt ies ditos; y den, y sian tenidos los ditos Viario, y Mayordomne, ó Deputado en lugar de aquel, dar conta en cada un anio de las ditas destribuicones, y paga de cada vna dellas, al Capitol de los Confrayres de Santa Fè, o aquellos Contadores que por el dito Capitol deputados hi ferán, por tal que las ditas destribuiones, y pagas de cada una dellas, el Capitol de los Cofrayres de la dita Cofrayria de Santa Fê, ó aquellos Contadores que por el dito Capitol diputados hi serán, por tal que las destribuiciones, y pagas, y cada una dellas sian feitas como se convengan, y fazer se devan, y pagadas las destribuciones sobreditas, y cada una dellas, lo que remandrá en cada un anio de los sobredichos treudos, y logueros mios de Zaragoça, y sus terminos; y de los sobredichos censales, y cada uno dellos, por mi a las ditas destribuciones, y cada una dellas lexados, y asignados, lo renderán, y restituirán en cada un anio, meins de algun embargo, y contradicion al heredero, ó herederos mios, ó adaquel, ô aquellos que yo querrè, ordenarè y mandarè, segunt ies dito. ITEM, de los otros bienes mios, ordeno 
ende, segunt se sigue: $^{8}$ PRIMERAMENT, lexo al postumo, o postuma, si la dita alta dona muller mia yes preñada, y en luz vendrà y a qualquiere otros fillos, y fillas que la dita alta dona, y de qualquiere otra muller mia legitima, que de aqui adelant avrè y Dios me querra dar, por part, y por legitima, de todos mis bienes muebles, y sedentes, a saber ies por todo moble, y sedient docinteos sueldos Jaqueses a cada uno dellos, se tengan por pagados, y contentos de su legitima part, y dreyto otro cualquiere que pudiessen demandar, y alcançar en mis bienes muebles, y sedentes, y cada uno dellos, segunt Fuero, y en otra qualquiere manera. ITEM, lexo de gracia especial al dito postumo, ò postuma si a la dita dona muller mia yes preñada, y en luz venrràn, segunt ies dito, todos los bienes mios/27 sedientes, a saber es, casas, censales, bodegas de vino, de olio con los vaxillos de fust de tierra que dentro aquellos son, y de si vinias, campos, piezas, olivares, huertos, y bienes otros sedientes mios, en qualquiere manera sian ditos, y nombrados, bien como si aqui cada unos por si por dos, tres, o mas confrontaciones $^{9}$ fuessen limitados, designados, y confrontados, que yo he, y ami se convienen, y pertenecen, y convenir, y pertenecer se me podràn, y deverán con cartas, o mĕos de cartas, y por otro qualquiere titol, caso, manera, ò razon, en la Ciudad de Zaragoça, y sus terminos, y en las Villas de Cariñena, y del Almunia, y sus terminos, y en Villareal, Berrbagena, Navarret, Gastons,$^{10}$ y Calamocha, Aldeas de Daroca, y sus terminos, y en qualquiere Villas, y Lugares otros del Reyno de Aragon, y en los terminos de aquellas; y ende fallimientto del dito postumo, ò postuma, fila dita muller mia yes preñada, y en luz vendrán, y de los fillos legitimos, y de legitimo matrimonio procreados de aquel, ò aquella que los ditos bines sedientes, y cada uno dellos sian, y tornen de gracia especial a los otros fillos, ò fillas mias legitimos, y legitimas que avré, y Dios me querrá dar de aqui adelant, que los partan por iguales partes excepto las casas mias mayores do yo havito, con los vaxielos de fust, y de tierra que dentro aquellas son, ò è encara las casas con las tinas contiguas a las ditas casas mayores mias, que sian, y aya ante part el fillo mio mayor; y caso do no huviesse fillos legitimos masclos, y huviesse una filla legitima, y no mas, que sian de aquella, y de los fillos de aquella legitimos, y de legitimo matrimonio procreados, con el vinculo, y condiciones dius scriptas, y si avrê mas de una filla legitimas, que sian de aquellas, y las partan por iguales partes, excepto las ditas casas mias mayores do havito, con los vaxillos de fust, y de tierra, de aquellas, y de las casas, y tinas contiguas a las ditas casas mayores, que sian de la filla mia mayor ante part, y apres sian los ditos bienes sedientes, y cada uno dellos de uno de los fillos legítimos de cada una de las ditas fillas mias, descendientes de recta linia de aquellas, empero con tal vinculo y condicion, $/ /^{28}$ que los fillos de las ditas fillas mias, y de cada una dellas, que los ditos bienes sedientes herederarán, y avrán, y cada uno dellos sian tenidos nombrar, y clamarse el sobrenombre de Capiella,

8 En la copia del notario Antón Calvo: «ies dito».

9 En la copia del notario Antón Calvo: «afrontaciones».

10 En la copia del notario Antón Calvo: «Santos». 
y fazer, y llevar mis armas dreitas, menos de alguna otra mezcla; y si por ventura el dito postumo, ò postuma, si la dita muller mia ies preñada, y en luz vendràn, a los otros fillos, y fillas mios legitimos, y legitimas que de aqui adelant avrè, y Dios me querrà dar; y los descendientes de recta linia de aquellos finaràn sines de fillos legitimos, y de legitimo matrimonio procreados, lo que Dios no mande; ó de los fillos legitimos de las ditas fillas mias, ó de qualquiere de aquellas, ni quisiessen clamarse el sobrenombre de Capiella, y fazer, y llevar mis armas dreytas, sines de alguna otra mezcla, segus ies dito; ó si la alta dona muller mia no serà preynada, ni avrè yo de aqui adelant filos, ò fillas legitimos, y legitimias, lo que Dios no mande, en los ditos casos, y cada uno dellos, quiero, mando, y ordeno que los dichos bienes sedientes, y cada uno dellos sian, y tornen de gracia special de uno de los fillos legitimo, y de legitimo matrimonio procreados, de la dita Florentica nieta mia, filla de los ditos Bellio Aznarez de Garden, y de Elvira filla mia qui fue, y de otro de los fillos legitimos, y de legitimo matrimonio procreados de la dita Margalitica filla mia, si los avrán, y en Orden processos no seràn, que los partan por iguales partes, excepto las casas mias mayores do havito, con los vaxillos de fust, y de tierra, y aquellas, y las tinas, y casas contiguas a las ditas casas mias mayores, que aya ante part el fillo de la ditta Florentica nieta mia; en tal manera empero, y condicion, que si la una de las ditas Florentica nieta mia, y Margalitica filla mia, finarà sines de fillos legitimos, y de legitimo matrimonio procreados, que los ditos bienes sedientes, y cada uno dellos sian, y tornen de gracia especial, de los fillos legitimos, y de legitimo matrimonio procreados de las ditas Florentica, y Margalitica, y de cada una dellas, y de los descendientes de las de recta linia de cada una dellas, que los ditos bienes sedientes de gracia especial avràn, y heredaràn, se nombren, y clamen, $/ /^{29} \mathrm{y}$ sian tenidos nombrar, y clamarse el sobrenombre de Capiella, y fagan, y lleven mis armas dreytas, menos de alguna otra mezcla, segunt ies dito, ò è encara con tal vinculo, y condicion, que quiero y mando caíado los bienes sedientes, y cada uno dellos, viengan, y ayan lugar en los fillos de las ditas Florentica, y Margalitica, y qualquiere dellas, que todos los ditos bienes sedientes, y vaxillos, y cada uno dellos tienga, reguia, adeministre, y espleyte el dito Juan de Capiella, y los tienga amillorados, y non piorados, y separe a todas, y cada unas cosas, cargas, y fazenderas que por razon de aquellos, y qualquiere dellos se ayan en qualquiere manera, a fazer tanto, y tan luengament, entro que los fillos de las ditas Florentica, y Margalitica sian de edad de catorze anios, y que dentro el dito tiempo el dito Juan de Capiella, dè y sia tenido dar por razon del pleyte, y usufruyto que avrá de los ditos bienes sedientes, y cada uno dellos en cada un anio dos mil cincientos sueldos Jaqueses de los quales quiero, que ayan dados cada un anio por provision, y mantenimiento de la dita Margalitica filla mia cincientos sueldos Jaqueses, entro que sia de edad sufient para casarsó è encara que apres de las ditas Florentica nieta mia, y Margalitica filla mia, y cada una dellas serán casadas, y avràn fillos, que quiero, y mando que los ditos mil cincientos sueldos sian dados a los sendos fillos de las ditas Florĕtica y Margalitica, que de los ditos bienes mios sedientes en la forma, y manera sobredita de gracia espe- 
cial, aver avràn seiscientos sueldos, a saber ies trecientos sueldos en cada dellos en cada un anio, tanto mentres seràn de pupillar edat, por razõ que se ayan que criar; y de los restantes dos mil sueldos en cada un anio, entro que la dita Margalitica serà de edad suficient para casar; y apres que las ditas Florentica, y Margalitica casadas serán, y avrán fillos, a los quales se daràn para criar los ditos seiscientos sueldos, a saber ies trecientos sueldos a cada uno de ellos en cada un anio, para que se puedan criar de mientres seràn de pupilar edad, segun ies dito. De los restantes mil y novecientos sueldos en cada un anio de los ditos dos mil cincientos sueldos, $/ /^{\beta 0}$ que el dito Juan de Capiella serà tenido dar en cada un anio, segun ies dito, entro tanto que los ditos dos fillos de las ditas Florentica, y Margalitica, sian de edad de cada catorze anios, segun ies dito, quiero, y mando que por mis Espondaleros dius scriptos, sian comprados treudos perpetuos en cada un anio, para paga de los dos mil trecientos setenta y dos sueldos seis dineros de la provisision de cada un anio de los ditos pobres, y mil sueldos para casar huerfanas en cada un anio, y mil sueldos para destribuir en cada un anio a vegonçantes, y cient y vint sueldos de los ditos Aniversarios, y cient sueldos de salario de los ditos Vicario, y Mayordomne, ò Deputado en lugar del dito Mayordomne por Capitol de los Confrayres de la dita Confrayria de Santa Fè, a fazer en cada un anio las ditas pagas, siquiere destribuciones, y cada una dellas, segun ies dito, y por mi de part de suso mandado, y ordenado. ITEM, encara que si las ditas Florentica nieta mia, y Margalitica filla mia, finaràn sines de fillos legitimos, y de legitimo matrimonio procreados, o si los fillos legitimos de las que los ditos bienes mios sedientes de gracia especial avràn, y los descendientes dellos de recta linia finarán sines de fillos legitimos y de legitimo matrimonio procreados, lo que Dios no mande, ò de los fillos de las ditas Florentica, y Margalitica, que los ditos bienes sedientes de gracia especial, segunt ies dito avràn, y los descendientes de recta linia de aquellos no se querràn clamar, y fazer, y lebar armas dreytas de Capiella, menos de alguna otra mezcla, segunt ies dito, en los ditos casos, y cada uno dellos, quiero, mando, y ordeno que las ditas casas mayores mias do yo havito, con los vaxillos de fust, y de tierra que dentro aquellas son, y las tinas, y casas contiguas a las ditas casas mayores mias y las vincas mias de meçalfonada, que afrentan con carreras de dos partes, y con vinia de D. Iñigo de Liso qui fue, sian y finquen del fillo mayor del dito Joan de Capiella si lo avrà, y en Orden professo no serà; y todos los otros bienes mios sedientes, por mi de part de suso de gracia especial lexados, que se podràn buenament treudar que por mis Espõdaleros dius scriptos, sian dados a treudo perpetuo, $/ /{ }^{31}$ con luismo, fadiga, y comisso, ${ }^{11} \mathrm{y}$ con todas aquellas mas, $\mathrm{y}$ millores condiciones, que podràn, a proveyto de los ditos bienes, y cada uno dellos, y aquellos bienes sedientes que buena ment treudar no se podràn, que por los ditos mis Espondaleros sian vendidos los mas dantes, y de los precios de aquellos sian comprados mas treudos perpetuos buenos, y seguros, y sian cumplidas, y pagadas todas las lexas, destribuciones, y cosas otras sobreditas, y cada una de las

11 Vid. (González, 2009). 
por mi en en el present mi Testamnet lexadas, mandas, y ordenadas. ITEM, cumplidas, y exeguidas todas las lexas, obras, destribuciones, y cosas otras sobredichas, por mi de la parte de luso lexadas, y ordenadas, y cada una dellas, todos los otros bienes mios mobles, y sedientes, censales, y bienes otros, en cualquiere manera sian ditos, y nombrados, de los quales el present mi Testament non se aya feyto, ó faga especial mencion, lexolos al dito postumo, si la dita muller mia ies preynada, y en luz vendrà, $\mathrm{y}$ de si a qualesquiere otros fillos mios masclos legitimos, que de aqui adelant avrè, y Dios me querra dar, a los quales, y cada uno dito postumo, y de otros fillos mios masclos legitimos, lexolos por mi alma. A LA QUAL en el dito caso, lexo, y instituezco heredera mia universal, en tal manera, y condicion, que quiero y mando, que ende fallimiento del dicho postumo, y de otros fillos mios maíclos legitimos, segunt, ies dito, que los ditos bienes, y cada uno dellos, de los quales no aya feyto, ó faga especial mencion en el present mi Testament, segun ies dito, que por mis Espondaleros dius scriptos, sian todos vendidos, excepto los censales, y del precio, y precios que de los ditos bienes vendidos se avràn, y faliràn, en semble en las pensiones de cada un anio, de los ditos censales, y cada uno dellos, sian comprados treudos perpetuos, tanto quanto los precios de los ditos bienes vendidos cumplirán, y bastarán, en semble con las pensiones de los ditos censales, y cada uno dellos, de los quales treudos perpetuos, sian pagadas, y cumplidas las lexas, obras y cosas otras sobreditas, y cada una dellas, y sian encara feyto//32 cumplimiento de treudos perpetuos, para pagar en cada un anio los ditos dos mil trecientos setenta y dos sueldos seis dineros de cada un anio, de la provission de los ditos treze pobres y de los mil sueldos de la destribucion de cada un anio, para casar huerfanas, y de los mil sueldos de dar a vergonçantes cada un anio y de los cient y vint sueldos, de la destribucion de los ditos doze Aniversarios de cada un anio, y de los cient sueldos del salario de cada un anio de los ditos Vicario, y Mayordomne, ó Deputado en lugar del dito Mayordomne por el Capitol de los Confrayres de Sant Fè, segunt ies dito. Et todo lo sobredito cumplido, y pagado, de lo otro que romandrá de los ditos treudos perpetuos, quiero, y mando que sian dados en cada un anio a los dos fillos de las ditas Florentica nieta mia, y Margalitica filla mia, en los quales los ditos bienes mios sedientes, en los de gracia especial venrràn, y avràn, iuxta tenor de la sobredita mi ordinacion, dos mis sueldos Jaqueses a cada uno dellos, para mantenimiento de sus estamientos, despues que seràn de edad de catorze años, con los vinculos, y condiciones sobreditas y sobreditas. Et pagados los ditos cada dos mil sueldos en cada un anio a los fillos de la dita Florentica, y Margalitica ${ }^{12}$ por mantenimiento de sus estamientos, segunt ies dito, todo lo otro que sobre de los ditos treudos perpetuos, quiero, y mando, que en cada un anio sia expendido, y destribuido en aumentamiento

12 Hay que destacar que en la copia del notario Antón Calvo sólo al final del documento en alguna ocasión se indica «Margaritica»; en el caso de Florenza, en el documento del siglo XV no aparece con ningún tipo de diminutivo, mientras que en el texto impreso del siglo XVIII se refiere siempre a «Margalitica», «Florentica» o «Florencianita». 
de provission de mas pobres en cada un anio puen dar $^{13}(\mathrm{sic})$, dandoles seis dineros por dia a cada uno, y en mas huerfanas casar, y dar a pobres vergonçantes cada un anio, en remission de los pecados de las animas de los sobreditos, y mia. ITEM, por razon que en los ditos censales, ò alguno dellos han cartas de gracia, por las quales dentro de cierto tiempo los puedan comprar, ô quitar; quier, y mando que las ditas cartas les sian observadas ò è encara que cada, y quando los ditos censales, y qualesquiere dellos se quitarà, de los precios de aquellos, y de cada uno dellos, por los ditos mis Espondaleros dius scriptos, sian luego comprados treudos perpetuos para sustentacion, y paga de las destribuciones de la provission de $\operatorname{los} / /^{\beta 3}$ pobres, casar de huerfanas, y dar a pobres vergonçantes, y cumplir las pagas otras sobreditas, y cada una dellas, segunt ies dito ITEM, eslio Espondaleros mios, a los quales comando carament mi anima, y los ruego que sines danyio, y peligro de sus animas y bienes, cumplan, y exigan el present mi Testament, y todas, y cada unas cosas en el contenidas, a lo ante que podràn; es a saber, a los muy honoralbes, y discretos varones Don Juan Ximenez Cerdan, Cavallero Consellero del Señor Rey, y Justicia de Aragon; Mastre Juan Castel, Rector de Mora; Juan Ximenez de Valconcha, y Beltran de Cosco, Ciudadanos de la dita Ciudad, a todos en semble, ò la mayor partida dellos, en todo el tiempo de sus vidas, y apres dias dellos al Vicario de San Gil, con uno de los Mayordomnes que por tiempo de la dita Confraria de Santa Fè de la dita Iglesia serà, o con el dito Vicario en semble aquel qui por Capitol de los Confrayres de la dita Confrayria, en lugar del dito Mayordomne Deputado serà, a los quales, cada uno en su tiempo, y caso, do licencia, y poder pleno de cumplir, y exiguir todas las cosas sobredichas, y cada una dellas, por si, y por su propia autoridad, menos de licencia, y mandamiento de algun Juge; y que por el Papa, Arçobispo de Zaragoça, Oficial, Comissario, ò Deputado de ellos, ò de qualquiere dellos, ni por alguna otra persona Eclesiastica, ò Seglar, no puedan ser forçados, ni constreñidos a dar conta alguna de lo sobredito; en y entro a tanto que los fillos de las ditas Florentica nieta mia, y Margalitica filla mia, sian de la dita edad de cada catorze anios, y sian complidas, y pagadas todas las cosas sobredichas, y cada una dellas, segunt que de part de suso ies ordenado, y contenido. ITEM, quiero, y mando que por el Notario diuso scripto, a costa, y mission de mis bienes, sian dadas copias a cada uno de mis Executores del present mi Testament, si averlo querrán. Aquesto ies mi postrimero Testament, y ultima voluntad mia, el qual, y la qual quiero que valga por via de Testament, y ultima voluntad mia, segunt ies dito; y sino valia por via de Testament, y ultima voluntad mia, que valga por via de Codecillo, o por qualquiere $/ /^{34}$ otra millor, y mas firme via, y manera que de dreyto, de Fuero, uso, y buena costumbre del Reyno le pueda dezir, pensar, entender, y escrivir, a salvamiento, y firmeza de las antedichas cosas, y cada una dellas, Feyto fue esto en Zaragoça seis dias de Setiembre, anno à Nativitate Domini millesimo trecetensimo nonagesimo secundo: Testimonios son desto los honrados, y Religiosos Don Fray Pedro testis, Provincial de la Orden de

13 En la copia del notario Antón Calvo: «provendar». 
Santa Maria del Carmen de la Provincia de España, y Don Fray Martin Quinyonero, de la Orden de los Menores del Convento de Zaragoça. Sig †no de mi Sancho Martinez de la Peyra, Notario publico de la Ciudad de Zaragoça, qui a las sobredichas cosas present fui, y esto escrivir fiz en los presentes tres pargaminos juntados, ò cosidos con betas, ò correas de pargamino juntados ò cosidos. Et en primero pargamino ha LXXIIJ renglones, ò linias, y comiença la primera linia, ò renglon: En el nombre de Dios, y fenexe, como al; y comiença la ultima linia, ò renglon, dentro un mes, y fenexe, ditas Capellanias. Et en el segundo pargamino ha LXIX renglones ò linias, y comiença la primera linia, ò renglon, ni alguna dellas, y fenexe, edad serà; y comiença la ultima linia, los censales, y fenexe, bastantes a la. Et en el tercer pargamino ha LV renglones, ò linias, y comiença la primera linia, destribucion, y fenexe, fusters y cominça la ultima linia, Fray Martin, y fenexe, Convento de Zaragoça. Et ies escrito a mi dito Notario de sobre escriptos, do se lee en el primer pargamino en la xxu linia, de la dita Ciudad, en la XLIJ, linia, ITEM, lexo, quiero, y mando que sian dados de mis bienes a Sancho Pérez de Pila, Notario, en todo el tiempo de su vida para sustentacion de su estamiento ducientos sueldos Jaqueses en cada un anio; y en la XLVIIJ licencia fillos. Et en el doseno pargamino en la XJ. linia, aver Jaqueses; en la XIJ, por; en la XIIJ. linia, sobres; en la XxIIJ. linea, ditas en la XxJx, linia, Universidad, y en la XxxIIJ linia, tantos en la XXXvJ, linia, dita en la XLIIJ, linia, contenidas; en la XLJX linia, dos; en la L. linia de. Et en tercero pargamino, en la primera linia, ditos; en la vo linia, lebaràn, y en la XLIIIJ linia, $/ /{ }^{35}$ ditos. Et encara yes cierto a mi dito Notario, de raidos, y enmendados, do dizen en el primer pargamino, en la XXIJ linia, dormito; en la XXIIJ linia, creix; en la XXXVIJ linia, satisfacion; y en la LXIIJ linia, el. Et en doseno pargamino en v. linia, casos en la XXXv. linia, encara; y en la XLII linia, siquiere Alxama de. Et en el tercero pargamino en la XVIJ linia, otra; en la XXJX linia, Florentica de cada; en la XLIJ linia años, en la Lu linia, en; y en la LIJ linia, los ditos mis; y en la LIIJ linia, ò. Et dapnados con puntos, algunas partes duplicadas, en el dito primero pargamino en la Lx linia, sian tenidos pagar; y en la LXVIJ linia, trobado. Et en el dito tercero, siquiere pesent pargamino, en la XLJx linia, de San Gil; y raydo; y feyto una bergueta, ò rayeta. En la IJ linia del dito segundo pargamnio, entre las partes, ô dicciones, a los descendientes. Encara yes cierto a mi dito Notario, de raydos, y enmendados en las VIJ. y viIJ. linias, do dizen, anio, en la IJ linia, en; y en la IIJ. linia, los ditos mis; y en la LIIJ linia, ô. Et dapnadas con puntos, algunas partes duplicadas en el dito primero pargamino en la LX linia, sian tenidos pagar; y en la LXVIJ linia, trobado. Et en el dito tercero, siquiere present pargamino, en la XLJx linia de San Gil; y de raydo, y feyto una bergueta. Los quales raydos, y enmendados en las ditas vIJ. y viIJ linias, son de y la present sobre escripcion del signo mio present, y cerrè. 


\section{Referencias bibliográficas}

ARMILLAS, J.A. (1997), Historia de Zaragoza. La guerra de la Independencia y los Sitios, Zaragoza, Caja de Ahorros de la Inmaculada.

BLASCO, A. (2015), «Escribir la fe pública en la ciudad: los notarios» en P. Pueyo, (ed.), Lugares de escritura: la ciudad, XII Jornadas de la Sociedad Española de Ciencias y Técnicas Historiográficas (Zaragoza, 16 y 17 de junio de 2014), Zaragoza, IFC, 91-132.

BUENO, M. ${ }^{a}$ L. (2001), «La marginación y los desposeídos del amor» en M. L. Bueno (aut.), Espacios de vida y muerte en la Edad Media, Salamanca, Semuret, 469-519.

BURKE, P. (2006), Formas de Historia Cultural, Madrid, Alianza Editorial.

DEL CAMPO, A. (2006), «El discurso de la muerte en los fueros, observancias y ordinaciones del reino de Aragón», en C. González e I. Bazán, (dirs.), El discurso legal ante la muerte durante la Edad Media en el nordeste peninsular, Bilbao, Universidad del País Vasco, 425-454.

DEL CAMPO, A. (2011), El libro de testamentos de 1384-1407 del notario Vicente Rodilla una introducción a los documentos medievales de últimas voluntades, Zaragoza, IFC.

FALCÓN, M. a I. (1979), «Cofradías artesanales aragonesas en la Edad Media», Estado actual de los estudios sobre Aragón. Actas de las I Jornadas celebradas en Teruel del 18 al 20 de diciembre de 1978, (vol. 1), Zaragoza.

FALCÓN, M. a I. (1980), «Sanidad y Beneficencia en Zaragoza en el siglo XV», Aragón en la Edad Media, núm. 3, 183-226.

FALCÓN, M. I. (1997), Historia de Zaragoza. Zaragoza en la Baja Edad Media (siglos XIV-XV), Zaragoza, Caja de Ahorros de la Inmaculada.

GARCÍA, M. ${ }^{\text {a }}$ C. y FALCÓN, M. ${ }^{\text {a I }}$. (2006), «En torno a la muerte a finales de la Edad Media aragonesa», En la España Medieval, núm. 29, 153-186.

GAY, M. ${ }^{a}$ P. (1983), Iglesia de San Gil Abad, Catálogo documental. Zaragoza 13001600, Zaragoza, Los Sitios.

GONZÁLEZ, J.A. (2009), «La enfiteusis: aspectos básicos de esta institución», Revista de la Facultad de Ciencias Sociales y Jurídicas de Elche, vol. I, núm.4, 251-267.

IRANZO, M. ${ }^{\text {a }}$ T. (2014), «Las mujeres en la organización de los linajes de la baja nobleza aragonesa: los Anzano en el siglo XV» en M. ${ }^{a}$ C. García y C. Pérez, (coords.), Mujeres en la Edad Media: actividades políticas, socioeconómicas y culturales, Zaragoza, IFC.

LEVI, G. (1994), «La microhistoria», Indagación, núm. 0, 231-240.

MADOZ, P. (1981), Zaragoza en el diccionario de Pascual Madoz, II. Iglesias, conventos y hermandades o cofradías, Zaragoza, La Cadiera.

MAINÉ, E. (2006), Ciudadanos honrados de Zaragoza. La oligarquía zaragozana en la Baja Edad Media (1370-1410, Zaragoza, Grupo de Investigación y Excelencia CEMA. 
MARTÍNEZ, L. (2008), «Pobres, pobreza y asistencia en la Edad Media Hispana. Balance y perspectivas», Medievalismo, núm. 18, 67-107.

MIEDES, M. (1794), Origen y Estado del Colegio de los notarios del número de Zaragoza, Zaragoza.

NAVARRO, G. (2004), «Los notarios y el Estado aragonés (siglos XIV- XV)» en J.A. Barrio (ed.), Los cimientos del Estado en la Edad Media, Alicante, Marfil.

NAVARRO, G. (2006), «Las cofradías de la Vera Cruz y de la Sangre de Cristo en la Corona de Aragón (siglos XIV-XVI)», Anuario de Estudios Medievales, vol. 2, núm. 36, 583-611.

RODRIGO, M. ${ }^{\mathrm{a}}$ L. (2002), Testamentos medievales aragoneses. Ritos y actitudes ante la muerte (siglo XV), Zaragoza, Ediciones 94.

RUMEU DE ARMAS, A. (1944), Histora de la Previsión Social en España. Cofradías, Gremios, Hermandades, Montespíos, Madrid, Pegaso.

SAN VICENTE, A. (1965), El oficio de Padre de Huérfanos en Zaragoza, Zaragoza, Caesaraugustana Theses.

SAN VICENTE, A. (1998), Instrumentos para una historia social y económica del trabajo en Zaragoza en los siglos XV a XVIII, (2 vols.), Zaragoza, Real Sociedad Económica Aragonesa de Amigos del País.

TELLO, E. (2013), Aportación al estudio de las cofradías medievales y sus devociones en el reino de Aragón, Zaragoza, IFC.

TERUEL, M. (1993), Vocabulario básico de la Historia de la Iglesia, Barcelona, Crítica.

\section{Fuentes primarias}

ADZ, Archivo Parroquial de San Gil, Cofradía de Santa Fe, C3-10.

ADZ, Archivo Parroquial de San Gil, Cofradía de Santa Fe, C6-1.

ADZ, Archivo Parroquial de San Gil, Cofradía de Santa Fe, C6-2.

Adz, Archivo Parroquial de San Gil, Cofradía de Santa Fe, caja 26, núm.81.

ADZ, Archivo Parroquial de San Gil, Procesos Beneficiales, San Gil, caja 41, núm.82.

ADZ, Procesos Beneficiales, San Gil, f.313r.-f.314r.

ADZ, Registro Decretos, 1672-1682, f.19r.-f.25v.

ADZ, Registro Decretos, 1683-1687, f.234r.- f.239r.

AHN, Consejo de Castilla, Estado de las Cofradias, Hermandades y Congregaciones a la ciudad de Zaragoza junto con los pueblos de su jurisdicción, Consejos, 7105, Exp. 64, N.1, f.33. 